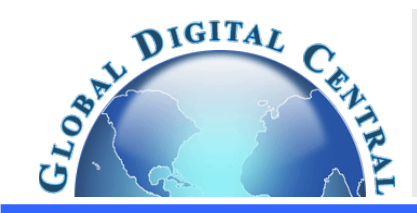

Frontiers in Heat and Mass Transfer

\title{
LAMINAR FORCED CONVECTION AND PERFORMANCE EVALUATION IN A SQUARE DUCT HEAT EXCHANGER PLACED WITH WAVY THIN RIB
}

\author{
Amnart Boonloi ${ }^{\mathrm{a}}$ and Withada Jedsadaratanachai ${ }^{\mathrm{b}, *}$ \\ ${ }^{a}$ Department of Mechanical Engineering Technology, College of Industrial Technology, King Mongkut's University of Technology North Bangkok, \\ Bangkok 10800, Thailand \\ ${ }^{b}$ Department of Mechanical Engineering, Faculty of Engineering, King Mongkut's Institute of Technology Ladkrabang, Bangkok 10520, Thailand
}

\begin{abstract}
Simulated examinations on convective heat transfer and flow topology in a square duct heat exchanger placed with wavy thin rib (WTR) are presented. The influences of WTR heights, pitch distances and flow directions on flow and heat transfer characteristics are investigated for the laminar flow regime at the inlet condition $(\mathrm{Re}=100-2000)$. The finite volume method (SIMPLE algorithm) is picked to analyze the numerical problem. The numerical validations; grid independence and verification of the smooth duct, are presented. The simulated results of the heat exchanger duct placed with WTR are reported in terms of flow and heat transfer visualizations. The relations of the $\mathrm{Nu} / \mathrm{Nu} 0, \mathrm{f} / \mathrm{f}_{0}$ and $\mathrm{TEF}$ with $\mathrm{Re}$ and $\mathrm{P} / \mathrm{H}$ in the heat exchanger square duct inserted with WTR are also plotted. The numerical result reveals that the heat transfer and friction loss increase when augmenting the Reynolds number and WTR height. The optimum pitch spacing ratio may give the highest heat transfer rate and thermal performance.
\end{abstract}

Keywords: Wavy thin rib; heat exchanger; heat transfer; thermal performance; numerical investigation.

\section{INTRODUCTION}

The improvement of the heat transfer rate for various types of the heat exchangers had been reported by many researchers. The development of the heat exchanger can be done both passive and active methods. The active method is the addition of the power such as vibration into the heating section to augment heat transfer rate. The passive technique is the installation of the vortex generator or turbulator such as rib, baffle, and winglet into the heating section to enhance the ability of heat transfer. In comparison, the passive technique can save operating cost than the active technique. The numerical and experimental investigations on convective heat transfer in the heat exchanger section with passive method had been reported by many researchers.

Bahiraei et al. (2020) presented the second law analysis in a square channel with V-shaped rib and nanofluid. The entropy generation and exergy destruction of the tested section were reported. The influences of rib height and rib pitch on flow topology and heat transfer characteristic in the channel were investigated. Bahiraei et al. (2019a) numerically studied the thermo-hydraulic performance of the $\mathrm{Cu}$-water nanofluid in a square channel inserted with $90^{\circ} \mathrm{V}$-shaped ribs on two opposite walls. The effects of rib height and rib pitch on convective heat transfer in the channel were considered. Bai et al. (2019a) experimentally investigated the heat transfer rate and pressure drop of pin-fin array enhanced with rib at the upstream. The configurations of the rib; V-shaped and Wshaped ribs, were compared for the Reynolds number around $7000-$ 40,000. They summarized that the rib at the entry regime can help to enhance heat transfer coefficient and reduce the pressure drop. Wang et al. (2019) reported the heat transfer increment in a micro-channel heat sink with bidirectional ribs both numerical and experimental investigations for $\mathrm{Re}=100-1000$. They found that the bidirectional ribs; vertical and spanwise ribs, can disturb the thermal boundary layer and induce recirculation. They also detected that the heat transfer rate in the micro-channel heat sink with bidirectional ribs enhances around $1.40-2.00$ and $1.20-1.42$ times when compared with vertical rib and spanwise rib, respectively. Luan et al. (2019) numerically studied the impacts of the connecting holes on flow topology and heat transfer profile in a two-pass channel with rib. The rib configurations and position of the connecting holes were considered for the $\operatorname{Re}=10,000$, 30,000 and 50,000. Liu et al. (2019) presented the impacts of rib arrangement on thermal performance of a parabolic trough receiver with ribbed absorber tube. They claimed that the present of rib can improve the Nusselt number around $1.41-3.21$ times above the plain tube. They also stated that the optimum enhancement in modified thermal efficiency is around $1.9 \%$. The application of a hybrid nanofluid containing grapheme nanoplatelet-platinum composite powder in a triple-tube with rib was reported by Bahiraei et al. (2019b). Li et al. (2019a) numerically and experimentally studied the heat transfer structure and friction loss in a channel with miniature structured rib on one wall for turbulent flow $(\mathrm{Re}=10,000-60,000$. The influences of rib types; miniature transverse, angled, V-shaped and W-shaped ribs, on flow and heat transfer profiles were considered. They concluded that the W-ribbed channel performs the averaged Nusselt numbers and overall Nusselt numbers of 2.20-2.60 and 2.903.30 times above smooth channel, while the friction factors is around 2.50-3.70 times higher than the smooth channel. Bai et al. (2019b) numerically investigated the pressure loss and heat transfer behavior of pin-fin array with rib turbulators. The numerical result revealed that the rib can induce the secondary flow in the heating system. The thermohydraulic performance enhancement in a micro-channel heat sink with triangular ribs on sidewalls was reported by Chai et al. (2019). The influences of rib geometry and arrangement on thermal performance were considered for the Reynolds number around $187-715$.

*Corresponding author.Email: kjwithad@kmitl.ac.th 


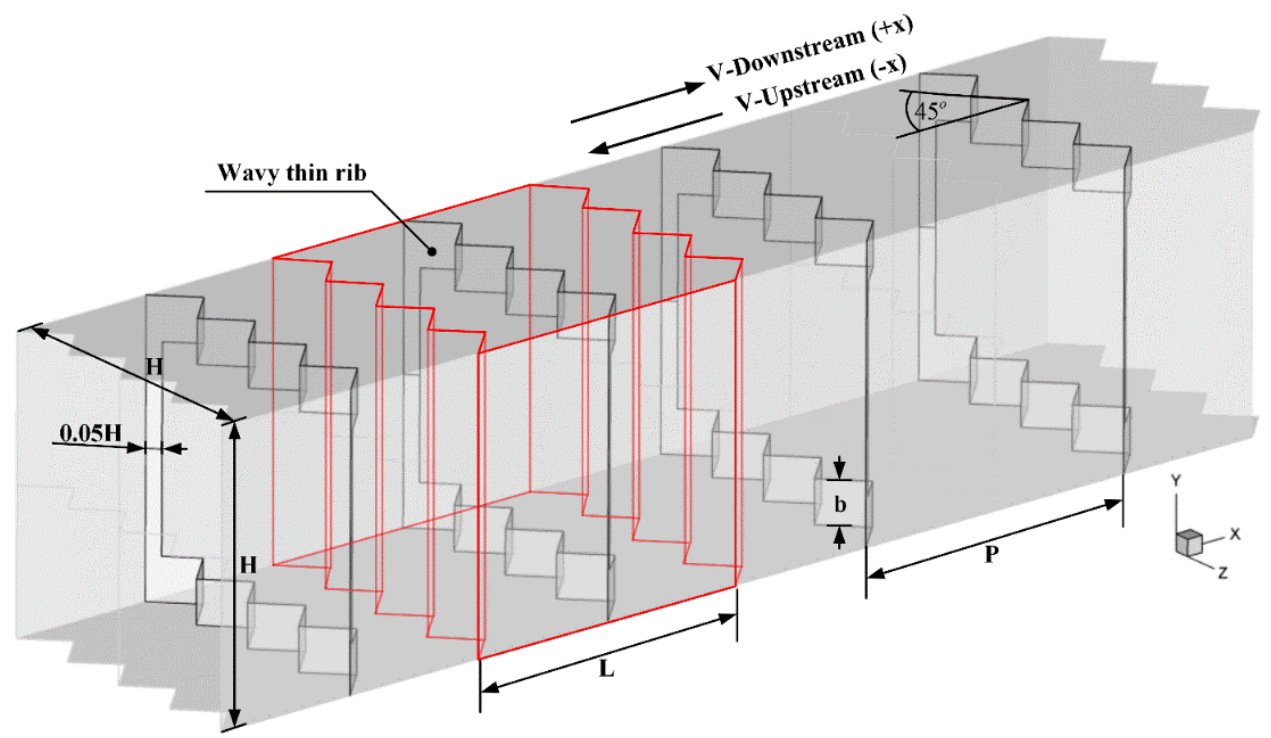

Fig. 1 Square duct heat exchanger inserted with WTR.

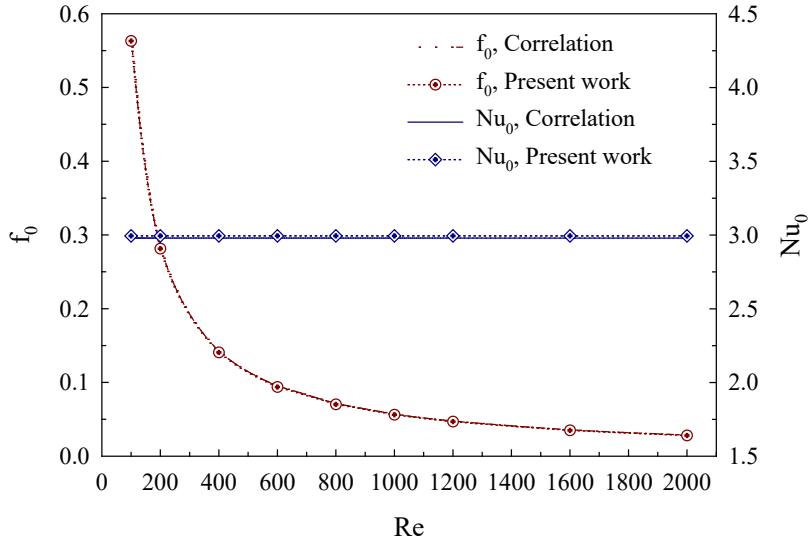

Fig. 2 Validation of the numerical model: verification of the smooth duct.

They concluded that the micro-channel heat sink with aligned triangular ribs gives the average Nusselt number and friction factor around $1.03-$ 2.01 and $1.06-9.09$ times above the reference straight micro-channel heat sink, respectively, while the micro-channel heat sink with offset triangular ribs provides the heat transfer rate and pressure loss around $1.01-2.16$ and $1.04-7.43$ times higher than the reference straight micro-channel heat sink, respectively. Yuan et al. (2020) presented the flow configurations and heat transfer profiles of supercritical pressure carbon dioxide in pipes with discrete double inclined rib. The numerical investigation on fluid flow and heat transfer structure in a microchannel heat sink with truncated rib on sidewall for $\mathrm{Re}=100-1000$ was reported by Wang et al. (2020). They found that the truncated rib in the micro-channel heat sink can improve the heat transfer rate and thermal performance. Patel et al. (2020) presented the convective heat transfer in a solar air heater with reverse NACA profile ribs for $\mathrm{Re}=$ $6000-18,000$. They summarized that the optimum thermo-hydraulic performance is around 2.53. Ahmed et al. (2019) reported the development of heat transfer ability for nanofluid in a duct with triangular rib at $\mathrm{Re}=4000-32,000$. The convective heat transfer in a rectangular channel installed with convergent and divergent slit ribs for $\operatorname{Re}=10,000-25,000$ was presented by Zheng et al. (2019). Li et al. (2019b) informed the augmentation on heat transfer rate in a channel with rib.

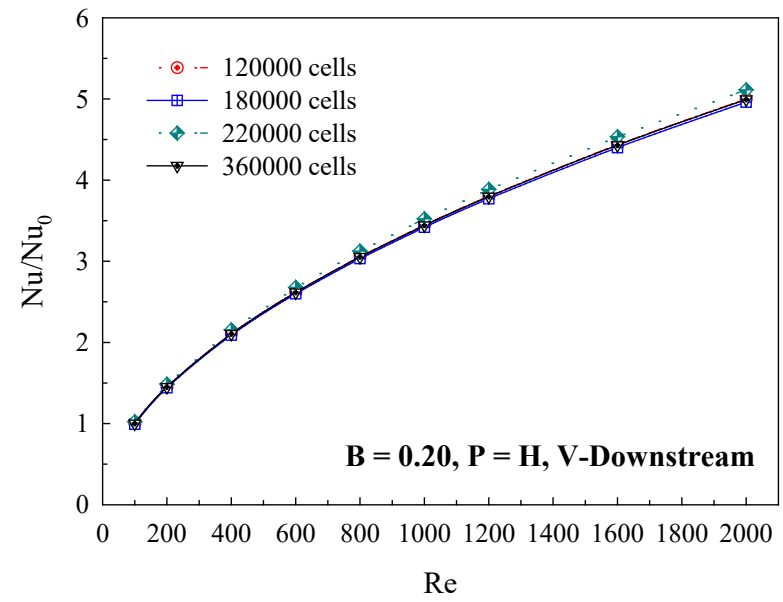

(a)

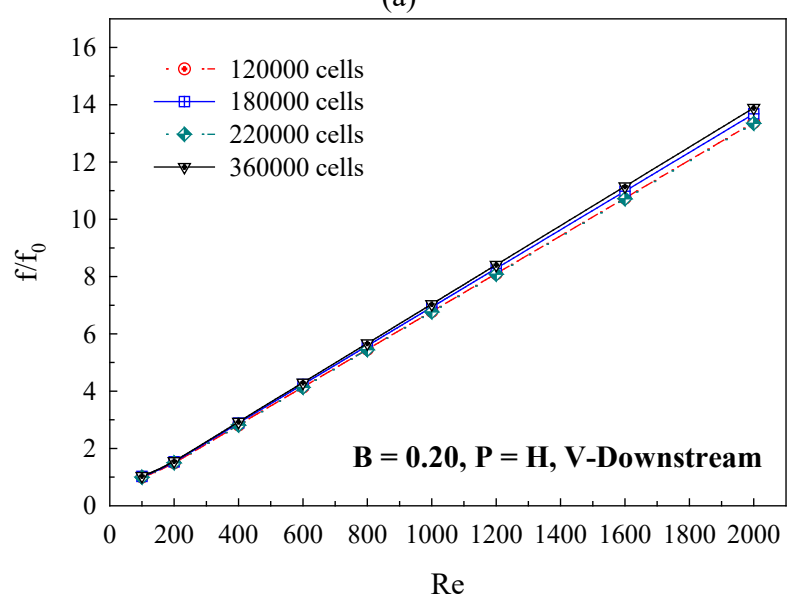

(b)

Fig. 3 Validation of the numerical model: grid independence for (a) $\mathrm{Nu} / \mathrm{Nu}_{0}$ and (b) f/fo.

In the present work, the passive technique is selected for the present work to remain the power cost of the process. The wavy thin rib or "WTR" is opted to enhance heat transfer rate in the heating section. The objective for the turbulator selection is to generate many vortex flows in the tested section. 


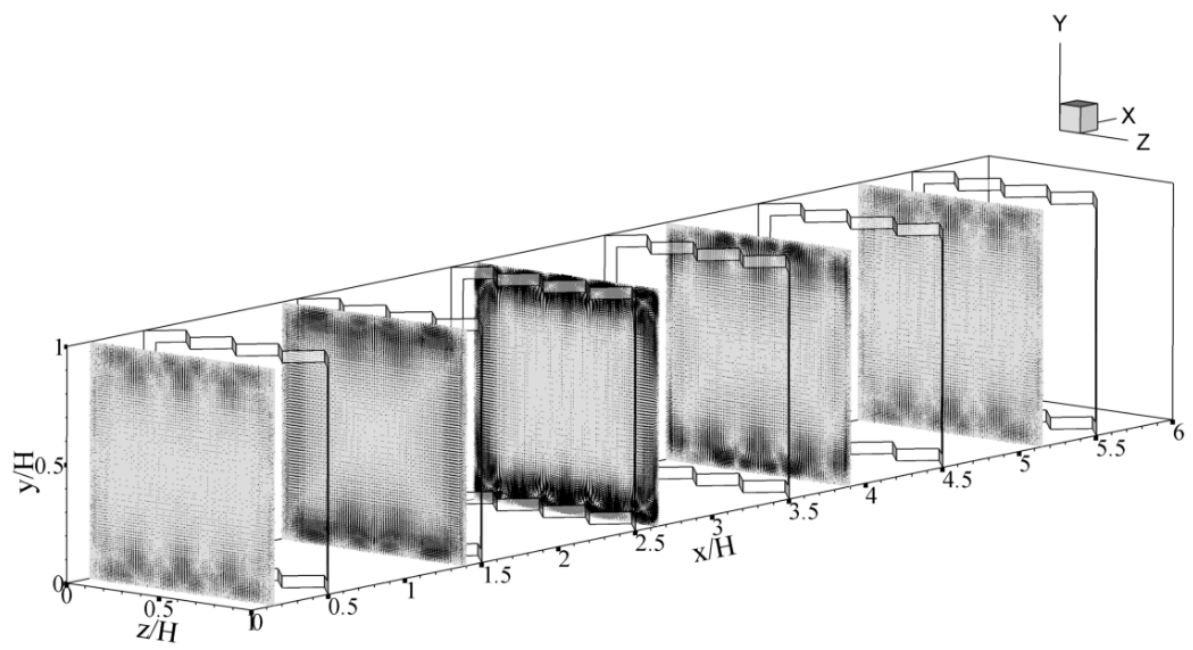

(a)

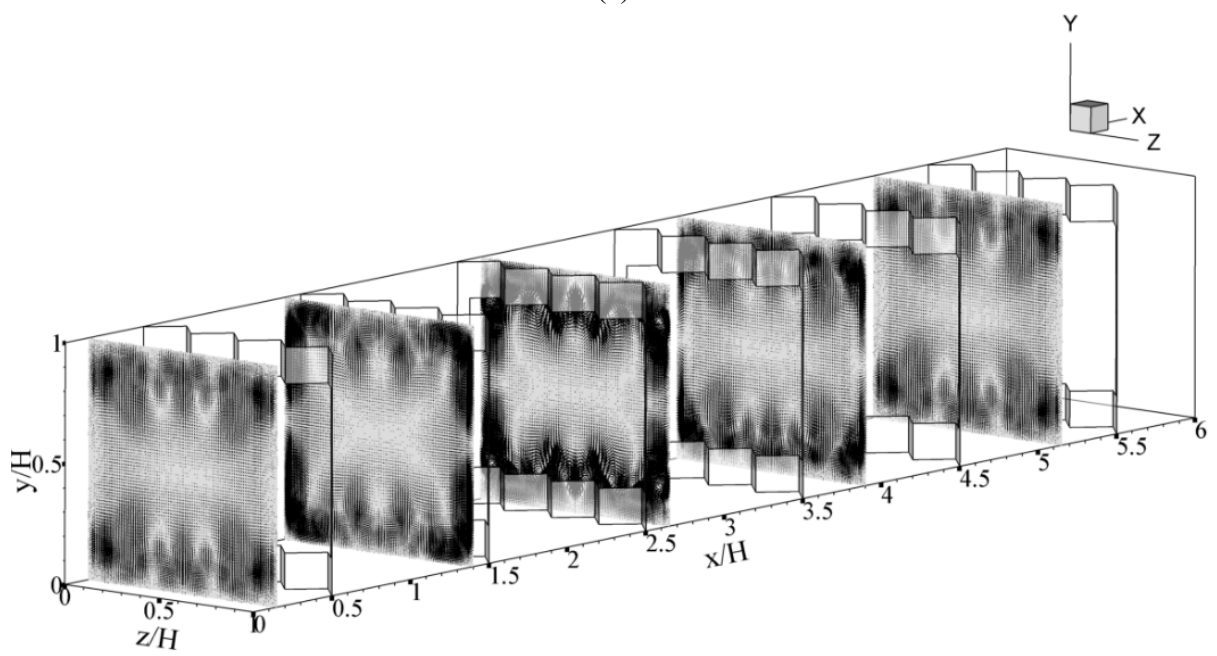

(b)

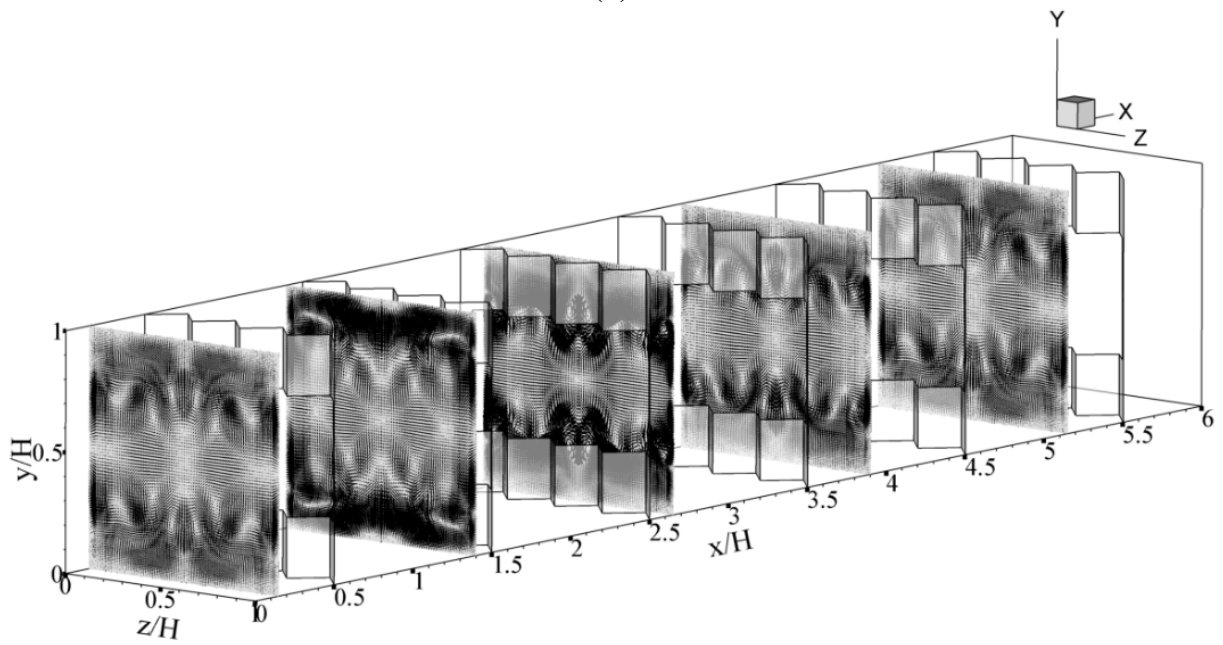

(c)

Fig. 4 Tangential velocity vector in $y-z$ planes for the heat exchanger duct inserted with WTR at $R e=600, P=H$ and $V$-Downstream of (a) $B=$ 0.05 , (b) $\mathrm{B}=0.15$ and (c) $\mathrm{B}=0.25$.

The wavy configuration can produce many cores of the vortex flows. The wavy configuration also helps to remain the pressure loss in the heat exchanger duct when compared with the other kinds of the turbulators. The many small vortices in the heat exchanger duct may reduce the bad region of the heat transfer ability, especially, at the corners of the heating duct. The parameters of the WTR and placement that effect for heat transfer and flow mechanisms in the heat exchanger are numerically investigated. The Reynolds number in laminar regime around $100-2000$ is considered for the current research. The creation model of the heat exchanger section is validated. The numerical result 
for the convective heat transfer in the heat exchanger duct is reported in kinds of flow and heat transfer mechanisms in the heating duct. The conclusion of the thermal performance (Nusselt number, friction factor and thermal enhancement factor) in the test section is also presented.

\section{PHYSICAL GEOMETRY OF SQUARE DUCT PLACED WITH WAVY THIN RIB}

The physical structure of the heat exchanger square duct equipped with WTR are depicted as Fig. 1. The duct height, $\mathrm{H}$, is equal to $0.05 \mathrm{~m}$. The width of the square duct is also equal to H. The WTRs are inserted in

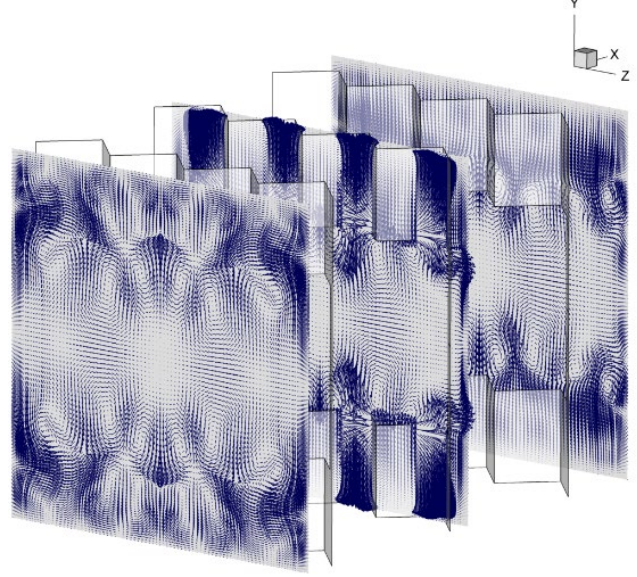

(a) the heat exchanger duct with pitch spacing ratio, $\mathrm{P} / \mathrm{H}=0.5,0.75,1$, 1.25 and 1.5. The flow blockage ratio, $\mathrm{b} / \mathrm{H}$ or $\mathrm{B}$, is varied in the range around $0.05-0.30$. The flow attack angle of the WTR is fixed around $45^{\circ}$ for all investigated cases. The Reynolds number around $100-2000$ (at the inlet condition) is considered for the present work. The flow directions of the tested section can separate into two parts: VDownstream $(+x)$ and V-Upstream $(-x)$. " $L "$ is the length of the periodic module for the tested section.

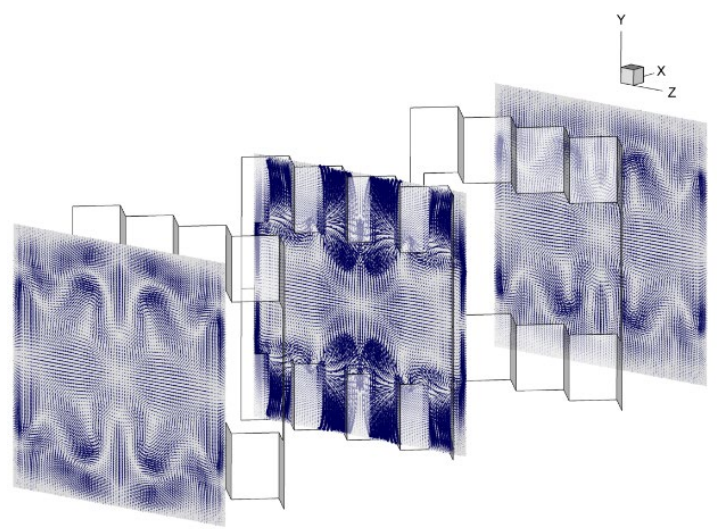

(b)

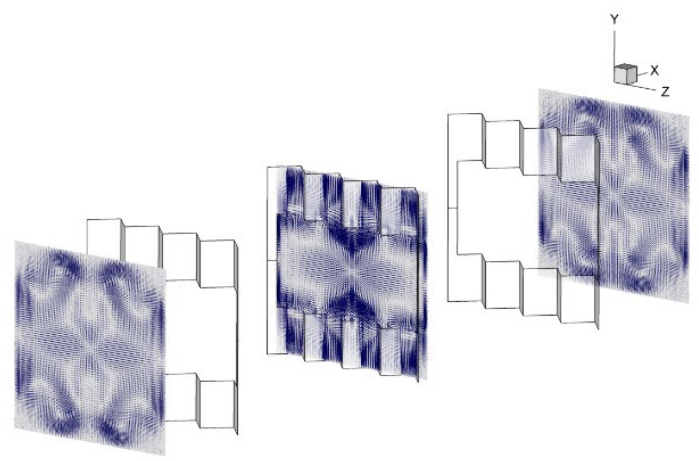

(c)

Fig. 5 Tangential velocity vector in $y-z$ planes for the heat exchanger duct inserted with WTR at $\operatorname{Re}=800, \mathrm{~B}=0.25$ and $\mathrm{V}$-Downstream of (a) $\mathrm{P}=$ $0.5 \mathrm{H}$, (b) $\mathrm{P}=\mathrm{H}$ and (c) $\mathrm{P}=1.5 \mathrm{H}$.

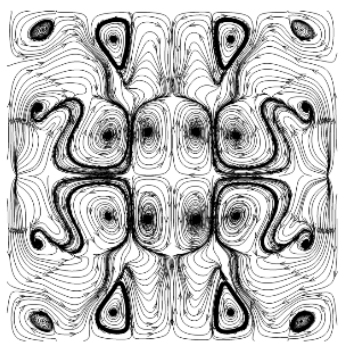

(a)

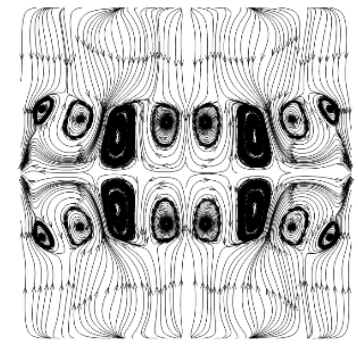

(b)
Fig. 6 Streamlines in $y-z$ plane for the heat exchanger duct inserted with WTR at $\mathrm{Re}=1000, \mathrm{~B}=0.30$ and $\mathrm{P}=0.5 \mathrm{H}$ of (a) VDownstream and (b) V-Upstream.

\section{NUMERICAL METHOD}

The laminar flow with the Reynolds number based on the hydraulic diameter at the inlet condition is considered for the present work. The fluid flow and heat transfer are steady in three dimensions. The tested fluid; air with $\operatorname{Pr}=0.707(300 \mathrm{~K})$, is set as incompressible flow. The thermal properties of the air are accepted to be constant at the average bulk mean temperature.

The convective heat transfer is considered for the present research, while the radiation and natural convection are disregarded. The body force and viscous dissipation are also disregarded. No slip wall condition is applied for all duct surfaces and WTR. The periodic boundary (Patankar et al. (1977)) on both flow and heat transfer is adopted for the inlet and outlet of the computational model. The WTR is counted to be insulator, while the duct walls are set with constant temperature around $310 \mathrm{~K}$.

The finite volume with SIMPLE algorithm is opted to solve the present problem. The present model is answered by the continuity equation, momentum equation and energy equation as equations 1,2 and 3 , respectively. 


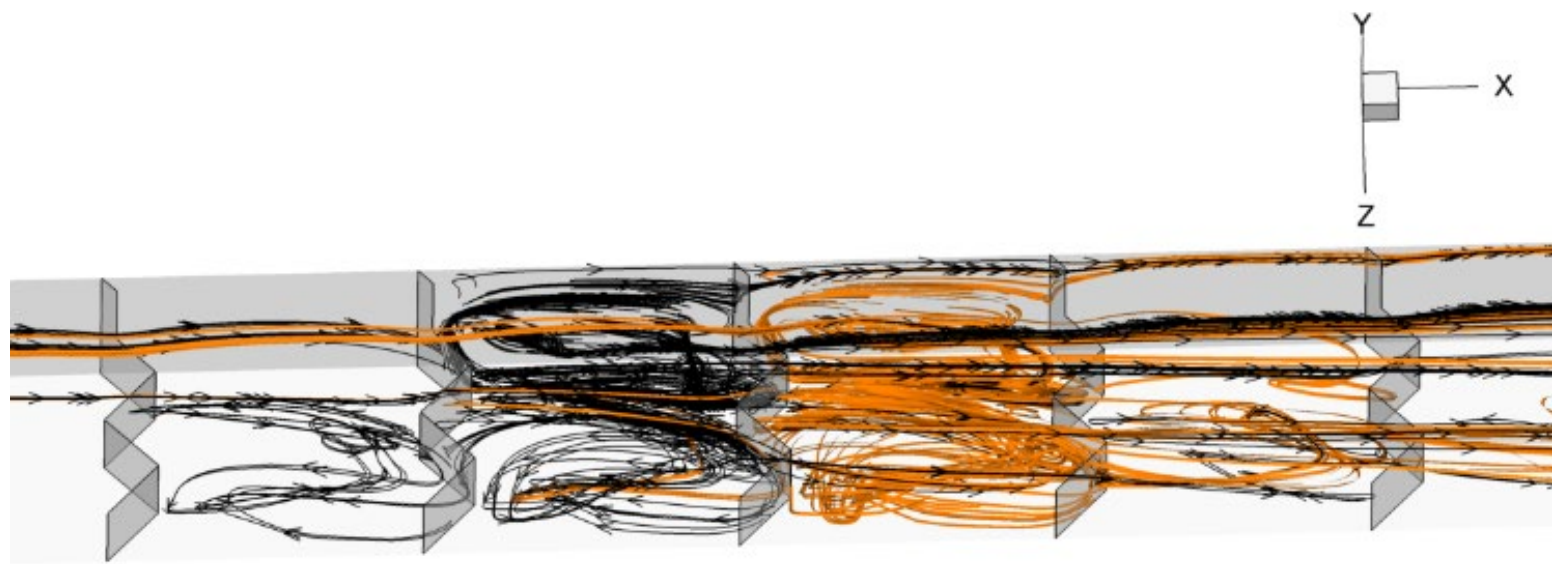

(a)

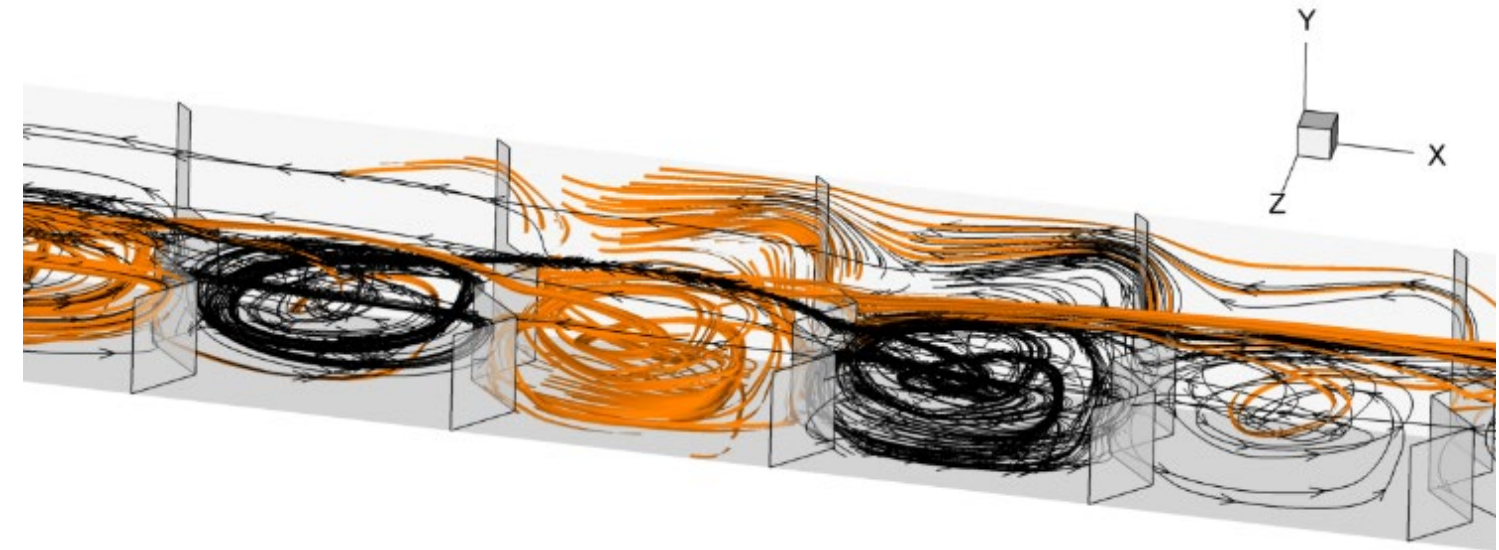

(b)

Fig. 7 Longitudinal vortex flow for the heat exchanger duct inserted with WTR at $\operatorname{Re}=1000, \mathrm{~B}=0.20$ and $\mathrm{P}=0.5 \mathrm{H}$ of (a) V-Downstream and (b) V-Upstream.

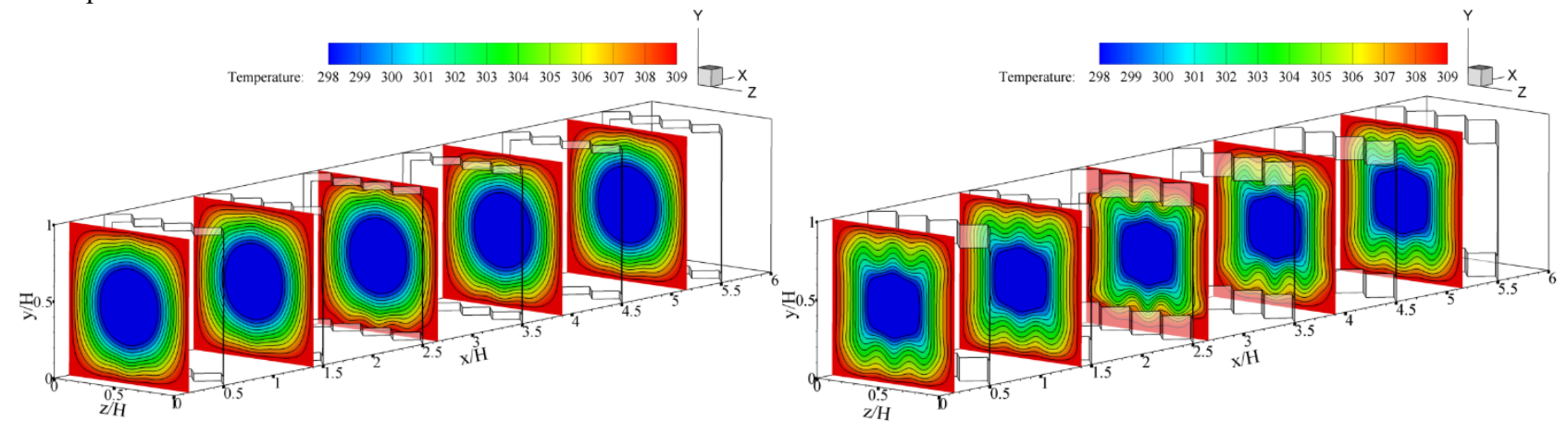

(a)

(b)

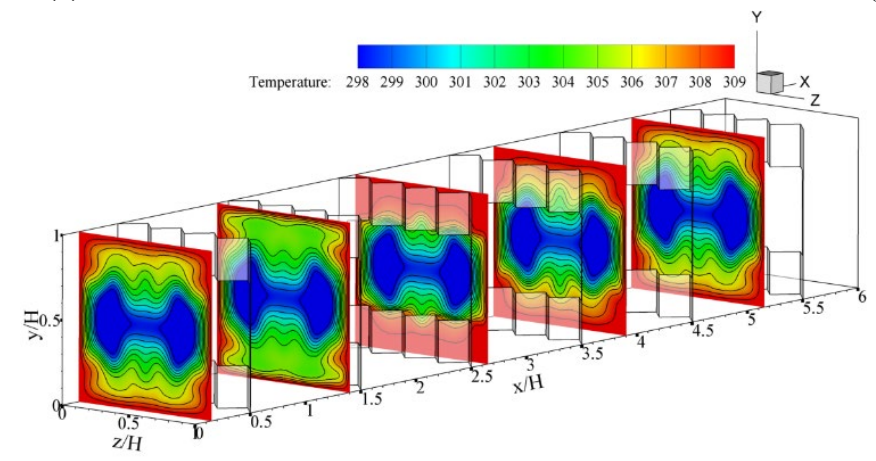

(c)

Fig. 8 Temperature distribution in y-z planes for the heat exchanger duct inserted with WTR at Re $=600, P=H$ and V-Downstream of (a) B = 0.05 , (b) $\mathrm{B}=0.15$ and (c) $\mathrm{B}=0.25$. 


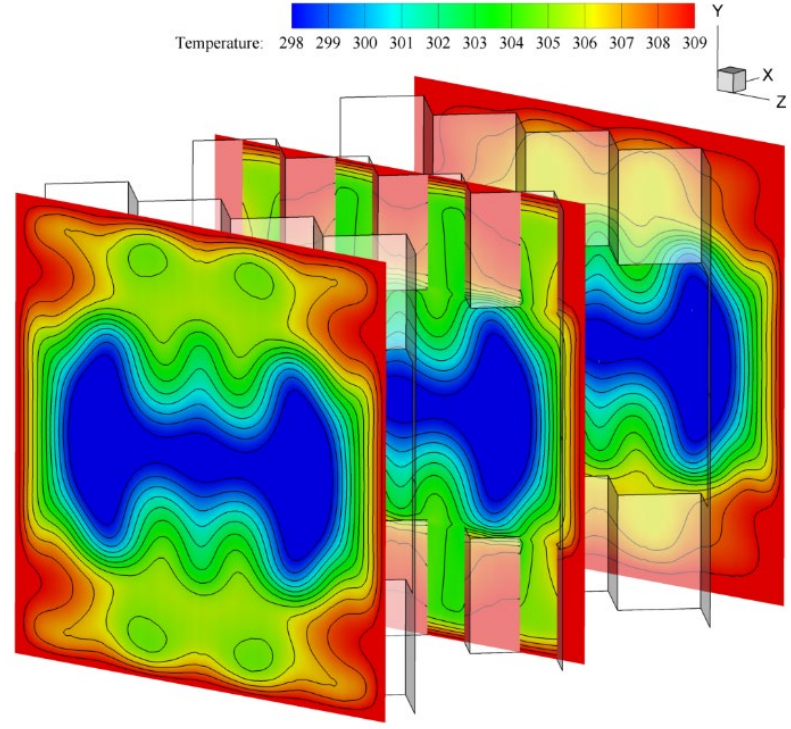

(a)

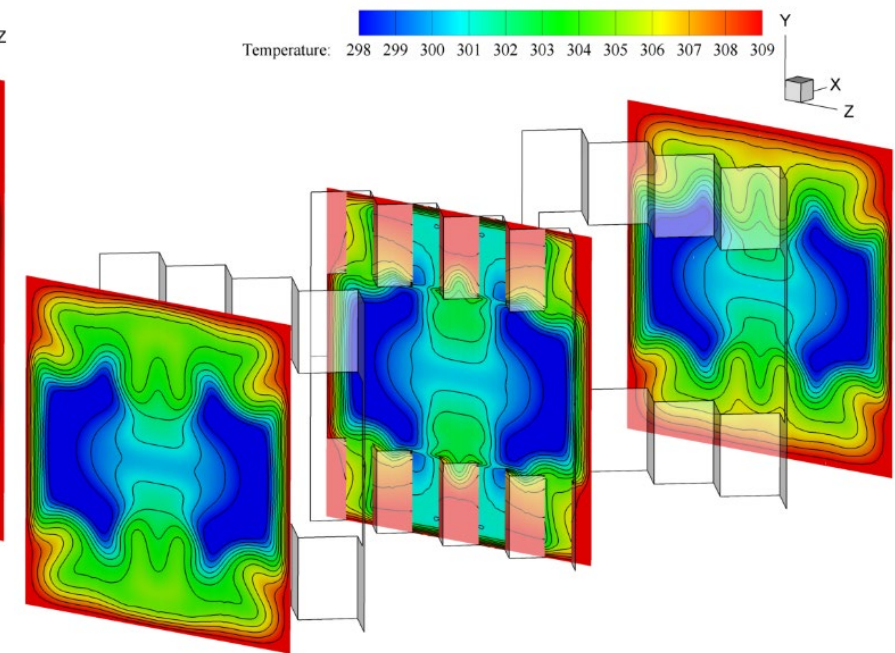

(b)
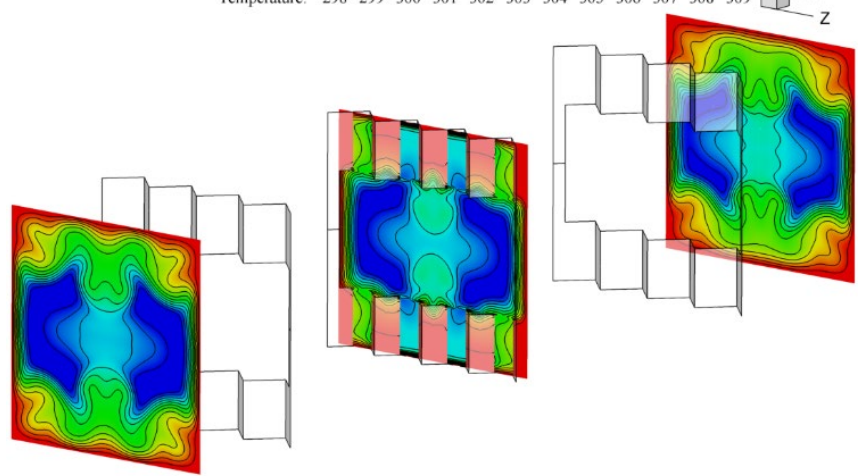

(c)

Fig. 9 Temperature distribution in $y-z$ planes for the heat exchanger duct inserted with WTR at $\operatorname{Re}=800, \mathrm{~B}=0.25$ and $\mathrm{V}$-Downstream of (a) $\mathrm{P}=$ $0.5 \mathrm{H}$, (b) $\mathrm{P}=\mathrm{H}$ and (c) $\mathrm{P}=1.5 \mathrm{H}$.

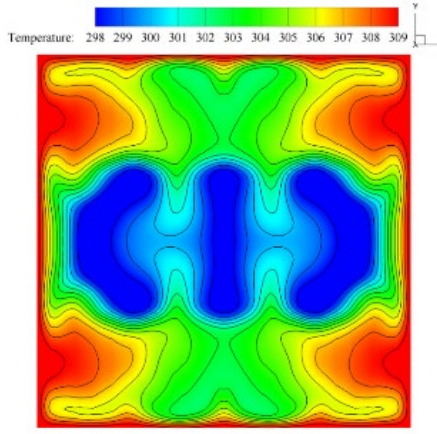

(a)

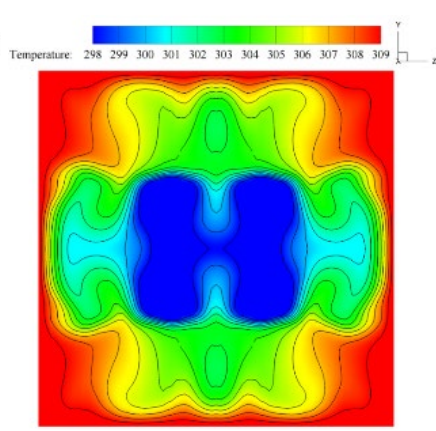

(b)

Fig. 10 Temperature distribution in $y-z$ planes for the heat exchanger duct inserted with WTR at $\mathrm{Re}=1000, \mathrm{~B}=0.30$ and $\mathrm{P}=0.5 \mathrm{H}$ of (a) V-Downstream and (b) V-Upstream.

The continuity equation, momentum equation and energy equation are discretized by the power law scheme, power law scheme and QUICK scheme, respectively. The numerical solutions are considered to be converged when the normalized residual values are less than $10^{-5}$ for all variables, but less than $10^{-9}$ only for the energy equation.

Continuity equation:

$\frac{\partial}{\partial x_{i}}\left(\rho u_{i}\right)=0$

Momentum equation:

$\frac{\partial\left(\rho u_{i} u_{j}\right)}{\partial x_{j}}=-\frac{\partial p}{\partial x_{i}}+\frac{\partial}{\partial x_{j}}\left[\mu\left(\frac{\partial u_{i}}{\partial x_{j}}+\frac{\partial u_{j}}{\partial x_{i}}\right)\right]$

Energy equation:

$\frac{\partial}{\partial x_{i}}\left(\rho u_{i} T\right)=\frac{\partial}{\partial x_{j}}\left(\Gamma \frac{\partial T}{\partial x_{j}}\right)$

where, $\Gamma$ is the thermal diffusivity and is written as follows:

$\Gamma=\frac{\mu}{\operatorname{Pr}}$

The air velocity is offered in term of the Reynolds number based on the hydraulic diameter of the square duct, $\mathrm{D}_{\mathrm{h}}$. The hydraulic diameter of the duct heat exchanger is equal to duct height $\left(\mathrm{D}_{\mathrm{h}}=\mathrm{H}\right)$. The Reynolds number can be computed by equation 5 .

$\operatorname{Re}=\frac{\rho \bar{u} D_{h}}{\mu}$ 

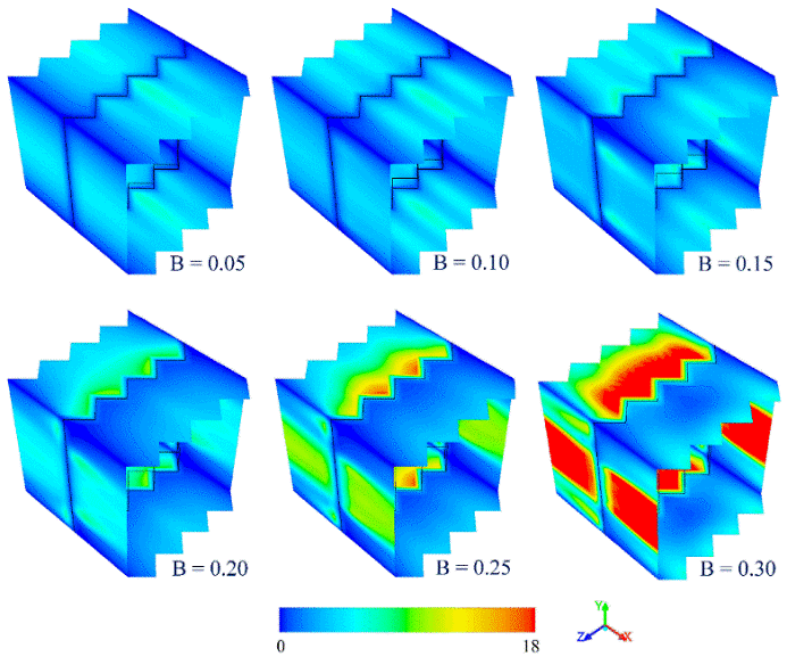

Fig. 11 Local Nussel number on the duct walls of the heat exchanger duct inserted with WTR at various blockage ratios for $\mathrm{Re}=$ $600, \mathrm{P}=\mathrm{H}$ and $\mathrm{V}$-Downstream.
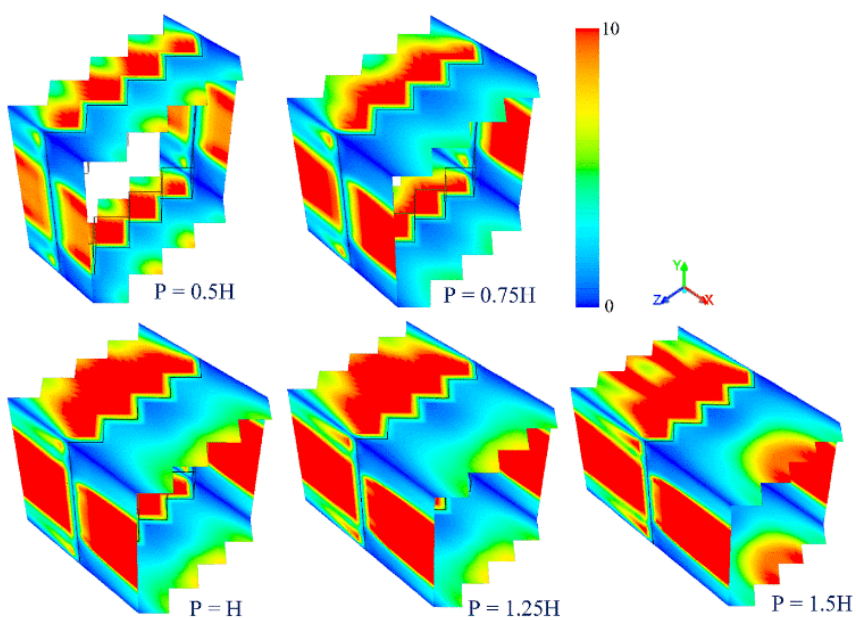

Fig. 12 Local Nussel number on the duct walls of the heat exchanger duct inserted with WTR at various pitch spacing ratios for Re $=800, \mathrm{~B}=0.25$ and $\mathrm{V}$-Downstream.

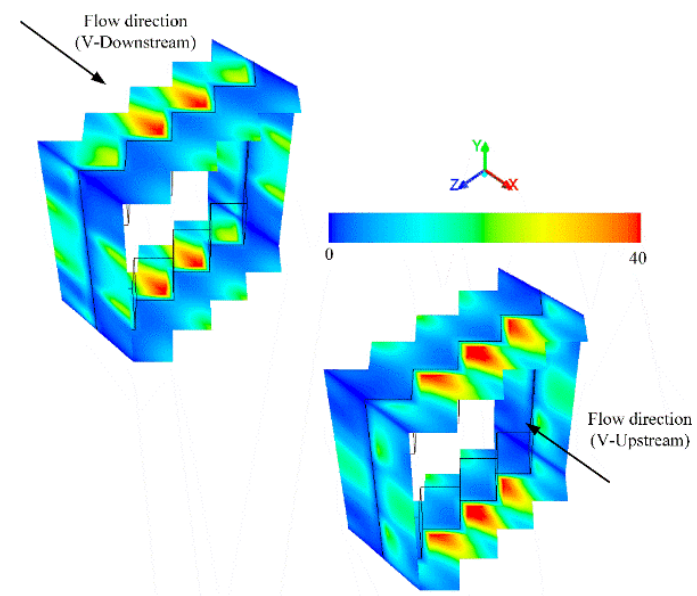

Fig. 13 Local Nussel number on the duct walls of the heat exchanger duct inserted with WTR at various flow directions for $\mathrm{Re}=$ $1000, \mathrm{~B}=0.30$ and $\mathrm{P}=0.5 \mathrm{H}$.
The friction loss of the duct heat exchanger placed with the $45^{\circ} \mathrm{WTR}$ is reported in form of friction factor. The friction factor can be calculated from equation 6 .

$f=\frac{(\Delta p / L) D_{h}}{\frac{1}{2} \rho \bar{u}^{2}}$

The heat transfer ability in the heat exchanger duct inserted with $45^{\circ}$ WTR is shown with the local Nusselt number and average Nusselt number as equations 7 and 8 , respectively.

$$
\begin{aligned}
& N u_{x}=\frac{h_{x} D_{h}}{k} \\
& N u=\frac{1}{L} \int N u_{x} \partial x
\end{aligned}
$$

The thermal performance in the heat exchanger duct inserted with $45^{\circ}$ WTR is reported in form of thermal enhancement factor or TEF as equation 9. The thermal enhancement factor is defined as the ratio of the heat transfer coefficient of an augmented surface, $h$, to that of a smooth surface, $\mathrm{h}_{0}$, at similar pumping power.

$$
T E F=\left.\frac{h}{h_{0}}\right|_{p p}=\left.\frac{N u}{N u_{0}}\right|_{p p}=\left(N u / N u_{0}\right) /\left(f / f_{0}\right)^{1 / 3}
$$

The $\mathrm{Nu}_{0}$ and $\mathrm{f}_{0}$ are the Nusselt number and friction factor for the smooth square duct, respectively.

\section{NUMERICAL VALIDATION}

The numerical model of the heat exchanger square duct inserted WTR is validated. The validation part is very important for the numerical investigation. The preliminary result in this part can enhance the reliance of the present investigation. The verifications of the numerical model can separate into two parts; verification of the smooth duct with no WTR and grid independence. The verification of the smooth square duct is done by compared the present results with the values from the correlations (Cengel and Ghajar (2015)) both Nusselt number and friction factor as Fig. 2. From the figure, the values from the correlations are in similar trend as the values from the present investigation. The deviations of the Nusselt number and friction factor are not higher than $0.50 \%$ and $1.20 \%$, respectively.

The grid independence of the numerical model for the heat exchanger duct placed with WTR is reported as Fig. 3. The different numbers of grid cells; 120000, 180000, 220000, 360000, are compared for the heat exchanger duct inserted with WTR at $\mathrm{B}=0.20, \mathrm{P}=\mathrm{H}$ and $\mathrm{V}$-Downstream direction. The numerical result reveals that the increment of grid cell higher than 120000 has no effect for both flow and heat transfer. Therefore, the grid cell around 120000 cells is adopted for all cases of the present examination. From the numerical result in this section, it can be concluded that creation model has high reliability to predict flow and heat transfer in the heat exchanger.

\section{NUMERICAL RESULT}

The numerical results for the heat exchanger duct placed with WTR are separated into five parts; flow and heat transfer structures, influence of Reynolds number, influence of blockage ratio, influence of pitch ratio and influence of flow direction.

\subsection{Flow topology and heat transfer}

The flow configuration in the heat exchanger duct equipped with WTR is presented in term of tangential velocity vector in transverse planes, streamlines in transverse planes and longitudinal vortex flow. The heat transfer characteristic in the tested duct inserted with WTR is plotted with temperature distribution in transverse planes and local Nusselt number on the heat transfer surface.

The tangential velocity vector in $y-z$ planes in the heat exchanger duct equipped with WTR are illustrated as Figs. $4 \mathrm{a}, \mathrm{b}$ and $\mathrm{c}$, respectively, for $\mathrm{B}=0.05,0.15$ and 0.25 , at $\mathrm{P}=\mathrm{H}, \mathrm{Re}=600$ and $\mathrm{V}$ Downstream arrangement. 


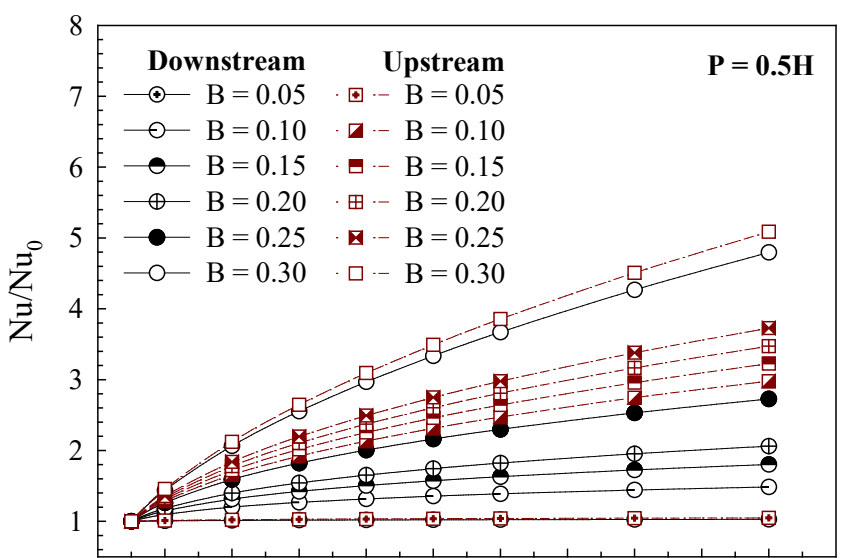

$0 \quad 200 \quad 400 \quad 600 \quad 8001000120014001600180020002200$

$\operatorname{Re}$

(a)

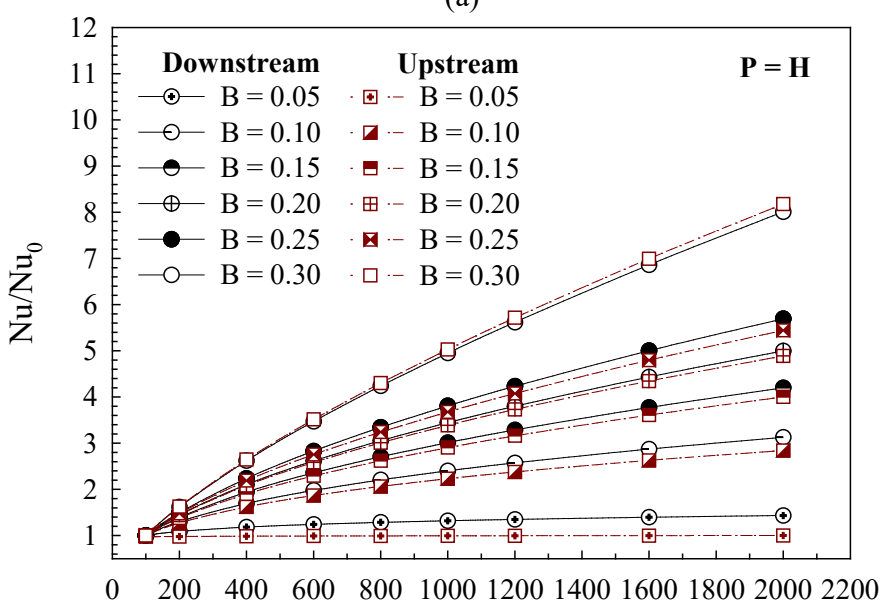

$\mathrm{Re}$

(c)

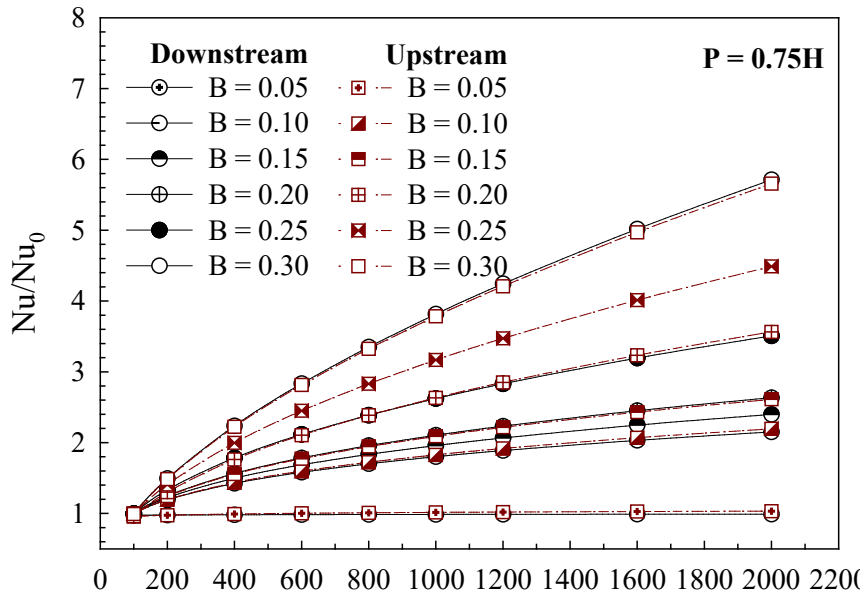

$\operatorname{Re}$

(b)

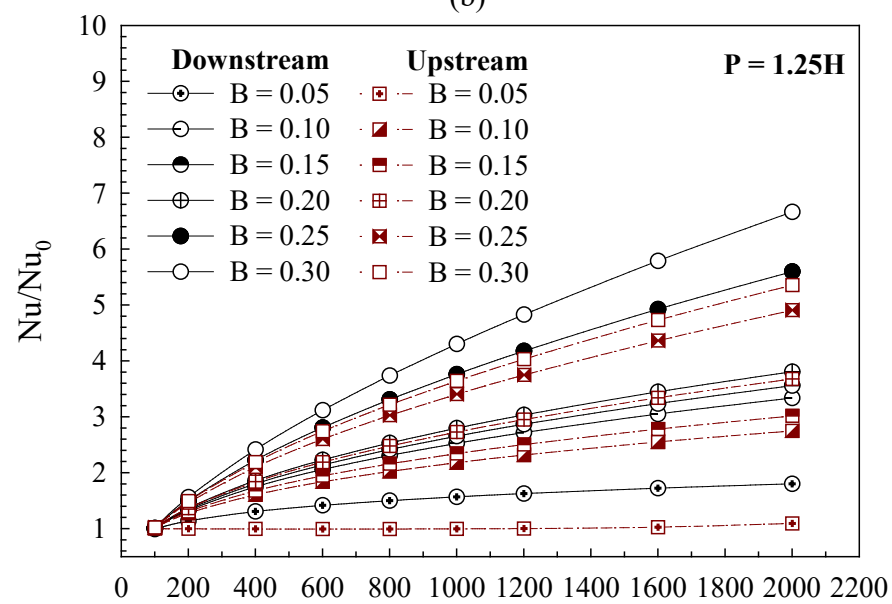

$\operatorname{Re}$

(d)

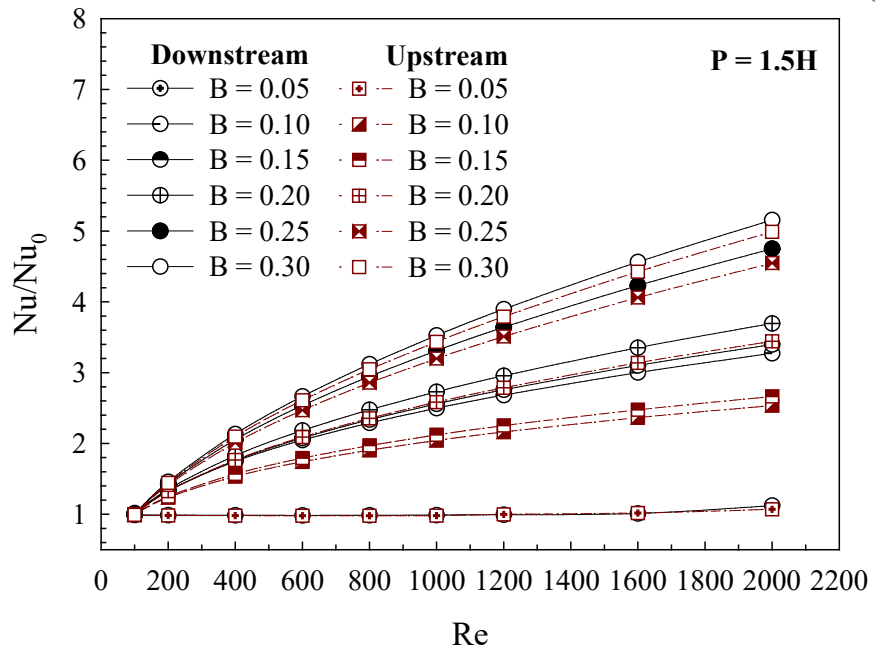

(e)

Fig. $14 \mathrm{Nu} / \mathrm{Nu}_{0}$ vs Re for (a) $\mathrm{P}=0.5 \mathrm{H}$, (b) $\mathrm{P}=0.75 \mathrm{H}$, (c) $\mathrm{P}=\mathrm{H}$, (d) $\mathrm{P}=1.25 \mathrm{H}$ and (e) $\mathrm{P}=1.5 \mathrm{H}$.

The WTR in the heat exchanger duct can product the vortex flow through the tested section, especially at high blockage ratio $(B>0.15)$. The strength of the vortex flow increases when enhancing the flow blockage ratio. The tangential velocity in transverse planes in the heat exchanger square duct placed with WTR is reported as Figs. 5a, b and c for the $\mathrm{P} / \mathrm{H}=0.5,1$ and 1.5 , respectively, of V-Downstream arrangement. The vortex flow in the tested section equipped with WTR is also detected when changed the $\mathrm{P} / \mathrm{H}$ values.
The streamlines in transverse planes in the heat exchanger duct equipped with WTR for V-Downstream and V-Upstream directions are shown as Figs. $6 \mathrm{a}$ and $\mathrm{b}$, respectively, at $\mathrm{Re}=1000, \mathrm{P}=0.5 \mathrm{H}$ and $\mathrm{B}=$ 0.30 . The longitudinal vortex flow in the heat exchanger duct inserted with WTR is plotted as Figs. 7a and b for V-Downstream and VUpstream arrangements, respectively, at $\mathrm{Re}=1000, \mathrm{~B}=0.20$ and $\mathrm{P} / \mathrm{H}=$ 0.5 . The variation of the flow direction leads to the change of the flow structure in the tested duct. 


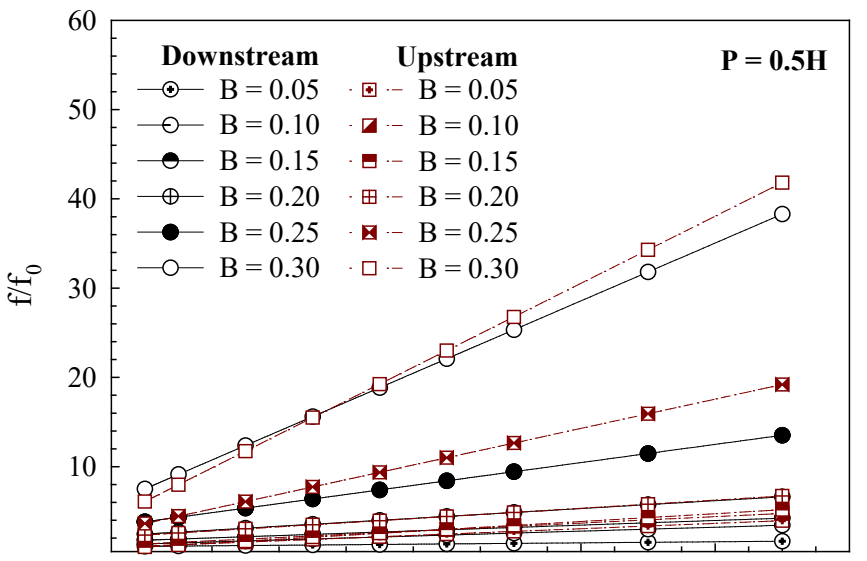

$0 \quad 200400600 \quad 8001000120014001600180020002200$

$\operatorname{Re}$

(a)

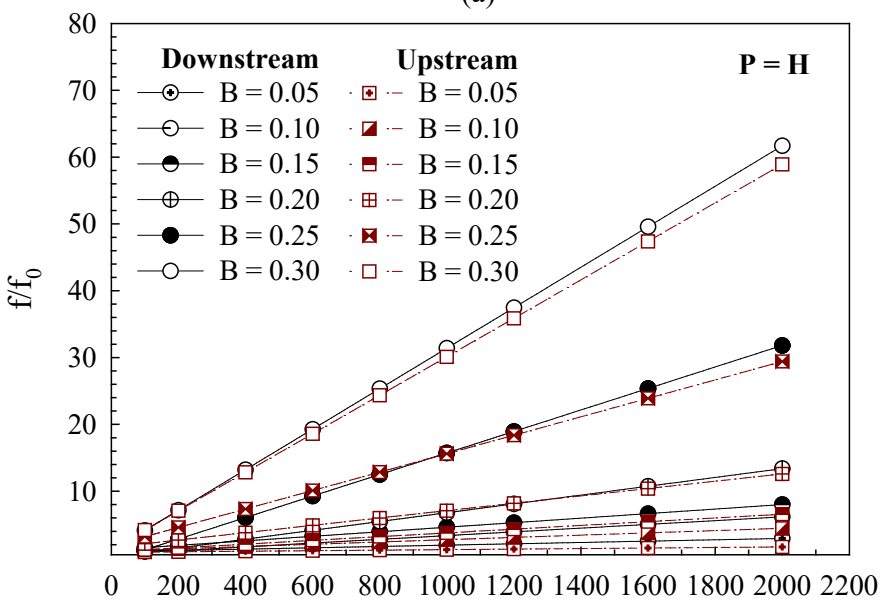

$\mathrm{Re}$

(c)

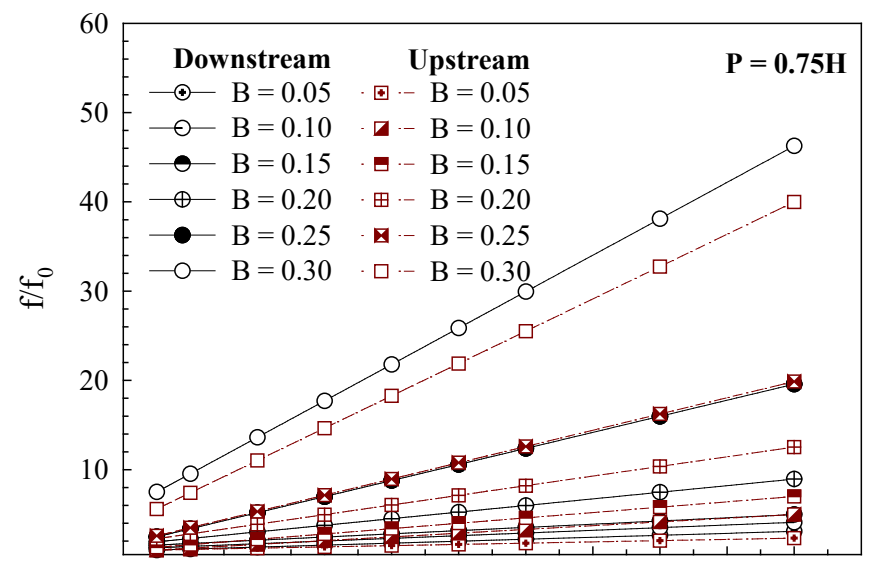

$0 \quad 200 \quad 400 \quad 600 \quad 8001000120014001600180020002200$

$\operatorname{Re}$

(b)

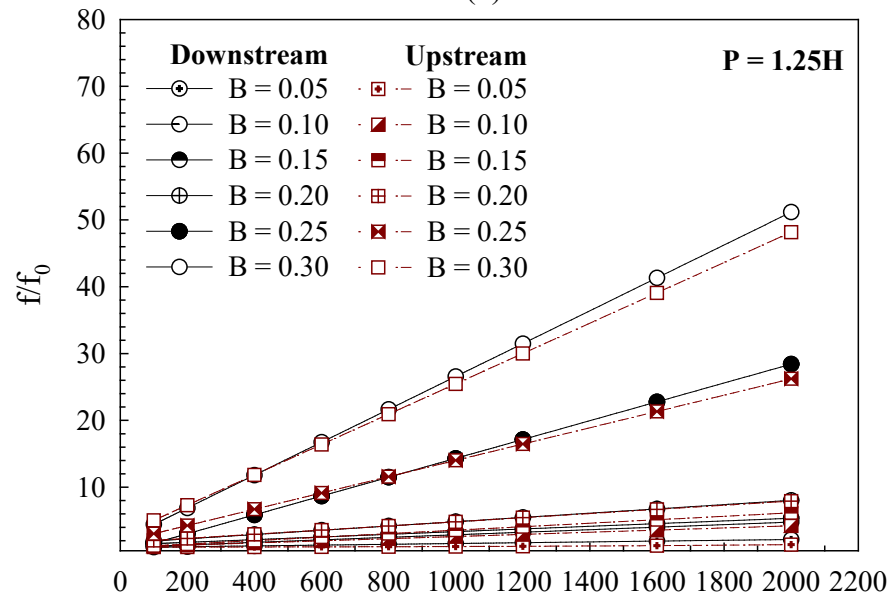

$\mathrm{Re}$

(d)

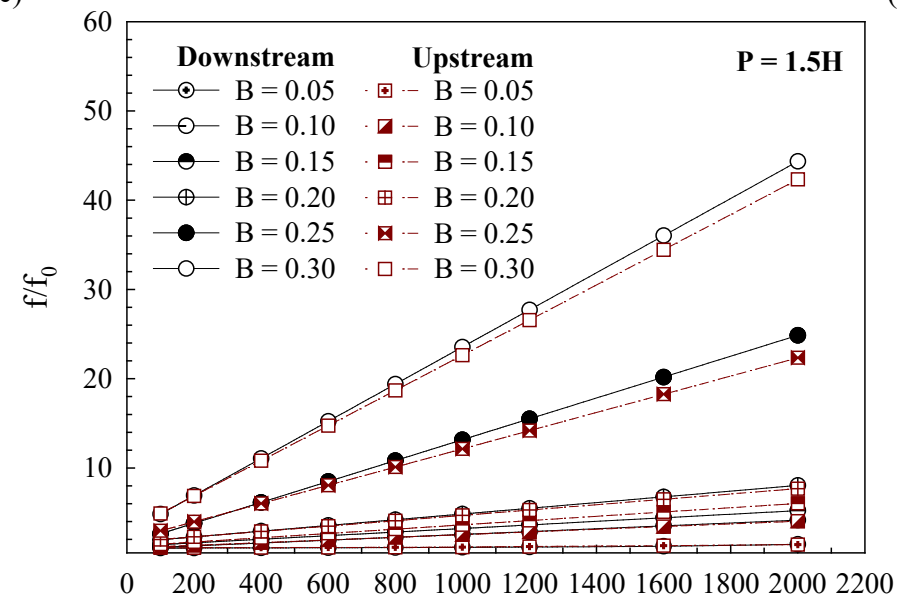

$\operatorname{Re}$

(e)

Fig. $15 \mathrm{f} / \mathrm{f}_{0}$ vs $\mathrm{Re}$ for (a) $\mathrm{P}=0.5 \mathrm{H}$, (b) $\mathrm{P}=0.75 \mathrm{H}$, (c) $\mathrm{P}=\mathrm{H}$, (d) $\mathrm{P}=1.25 \mathrm{H}$ and (e) $\mathrm{P}=1.5 \mathrm{H}$.

The change of the flow configuration effects for the change of the heat transfer behavior. This means that the peak of heat transfer regime may change when varied with flow direction.

The fluid-temperature distributions in $y-z$ planes in the heat exchanger duct placed with WTR are depicted as Figs. 8a, b and c for B $=0.05,0.15$ and 0.25 , respectively, at $\mathrm{Re}=600, \mathrm{P}=\mathrm{H}$ and $\mathrm{V}$ Downstream arrangement. The temperature profile of the heating section inserted with WTR at B $=0.05$ is similarly as the smooth duct with no WTR. The generation of the vortex flow in the heat exchanger section disturbs the thermal boundary layer on the duct walls.

The thermal boundary layer disturbance in the tested duct is obviously detected when increasing the flow blockage ratio. 


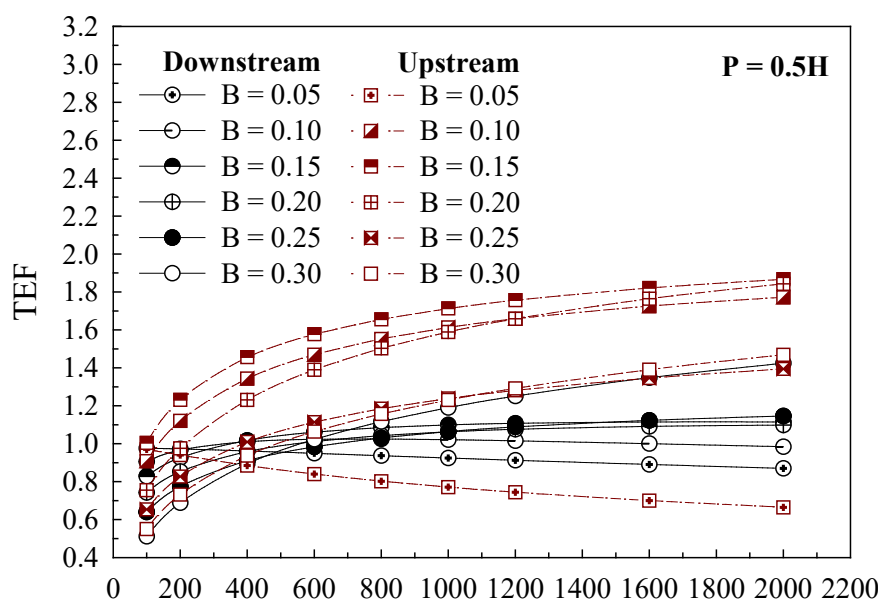

$\mathrm{Re}$

(a)

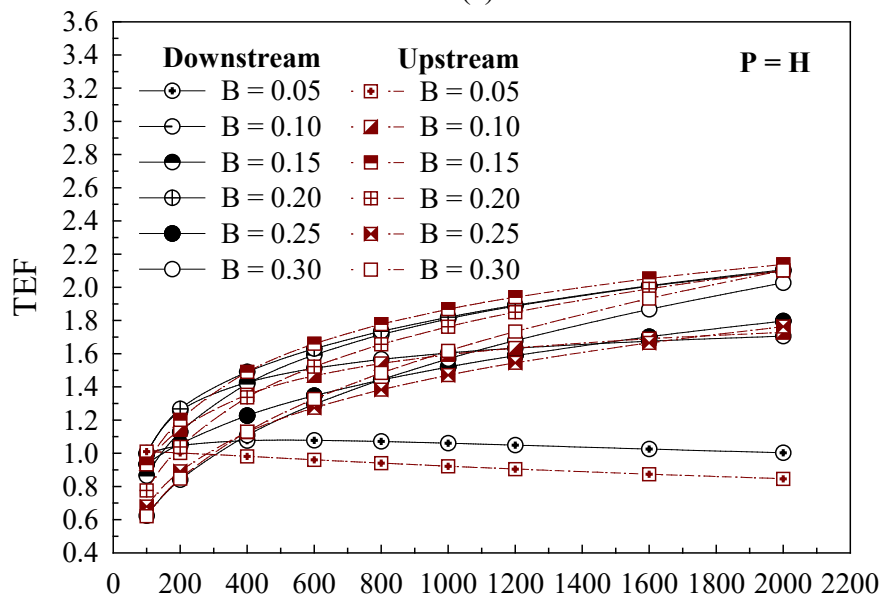

$\mathrm{Re}$

(c)

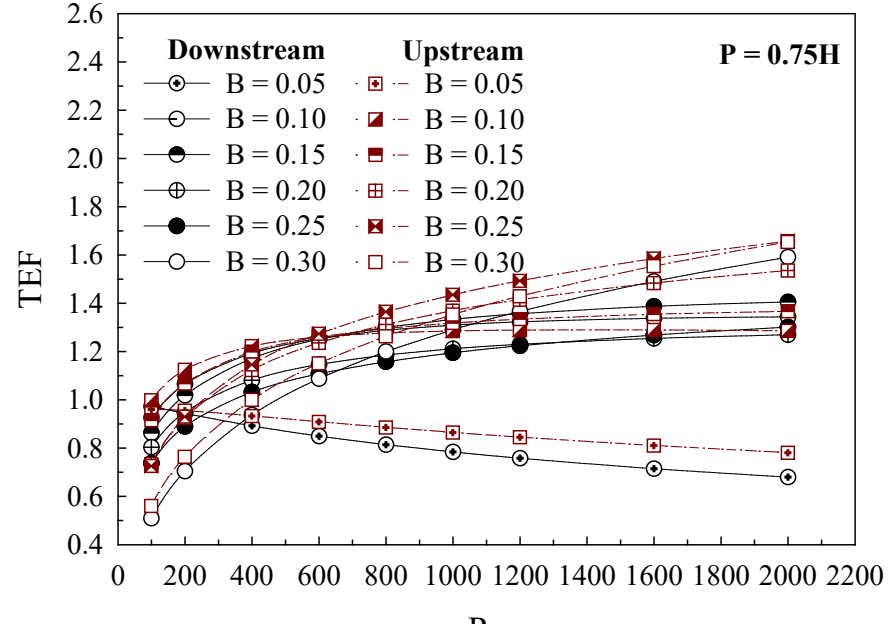

$\operatorname{Re}$

(b)

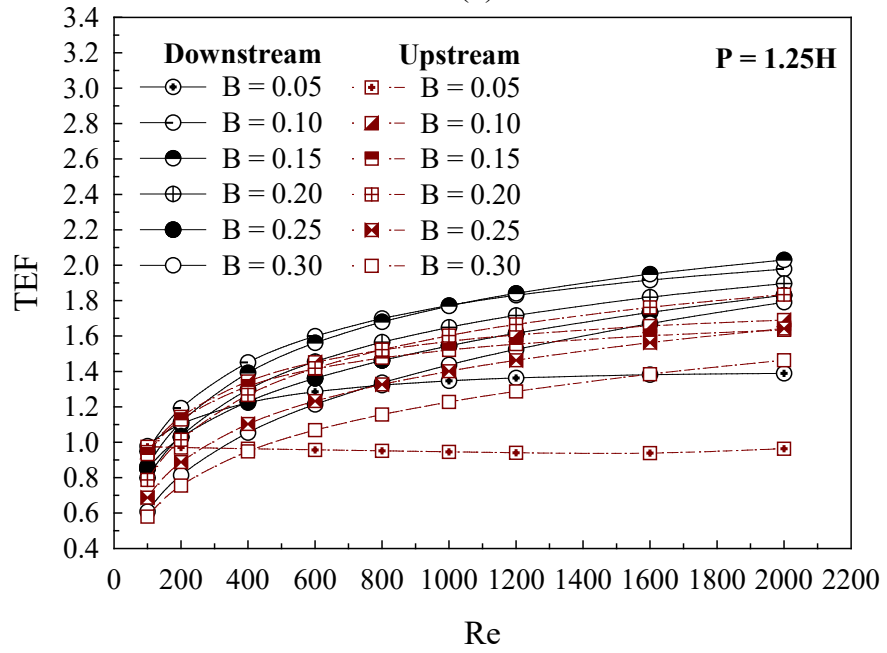

(d)

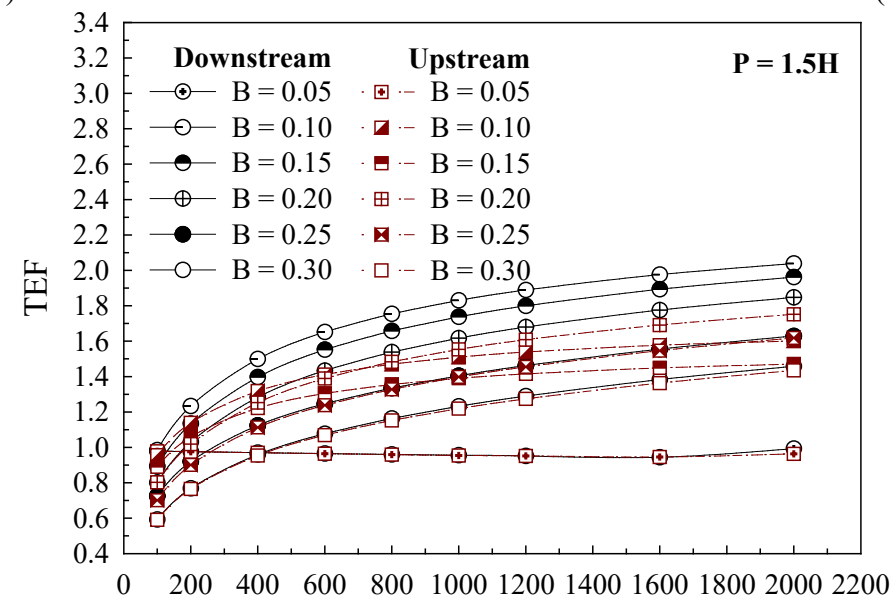

Re

(e)

Fig. 16 TEF vs Re for (a) $\mathrm{P}=0.5 \mathrm{H}$, (b) $\mathrm{P}=0.75 \mathrm{H}$, (c) $\mathrm{P}=\mathrm{H}$, (d) $\mathrm{P}=1.25 \mathrm{H}$ and (e) $\mathrm{P}=1.5 \mathrm{H}$.

The red layer (hot fluid temperature) near the duct wall seems to be decrease, while the blue layer (cold fluid temperature) distributes from the core of the duct. The disturbance of the thermal boundary layer on the heat transfer surface is also found when varied the pitch spacing ratio (see Fig. 9). The heat transfer profile is not in similar pattern when changed the flow directions (see Fig. 10).
The plots of the local Nusselt number on the duct walls for the heat exchanger duct equipped with WTR at various flow blockage ratio of $\mathrm{Re}=600, \mathrm{P}=\mathrm{H}$ and $\mathrm{V}$-Downstream direction are presented as Fig. 11 . The heat transfer behavior in the tested section has similar pattern in all blockage ratios. The heat transfer rate enhances when increasing the flow blockage ratio. 


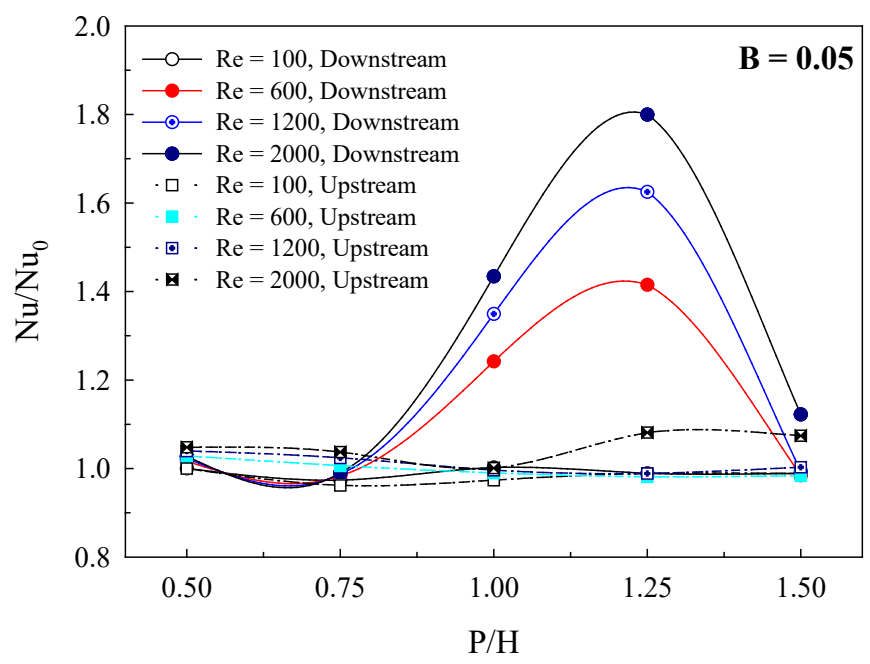

(a)

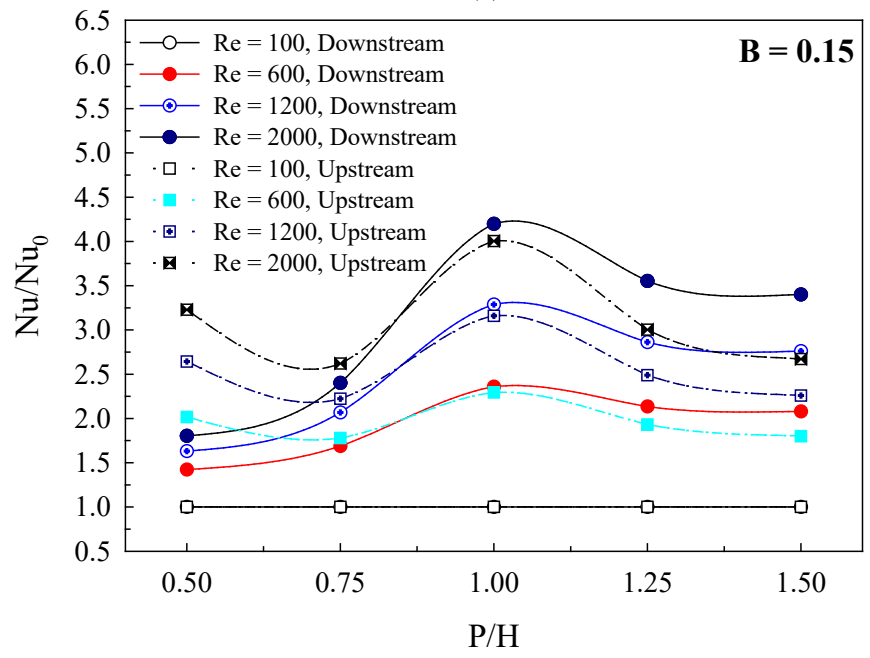

(c)

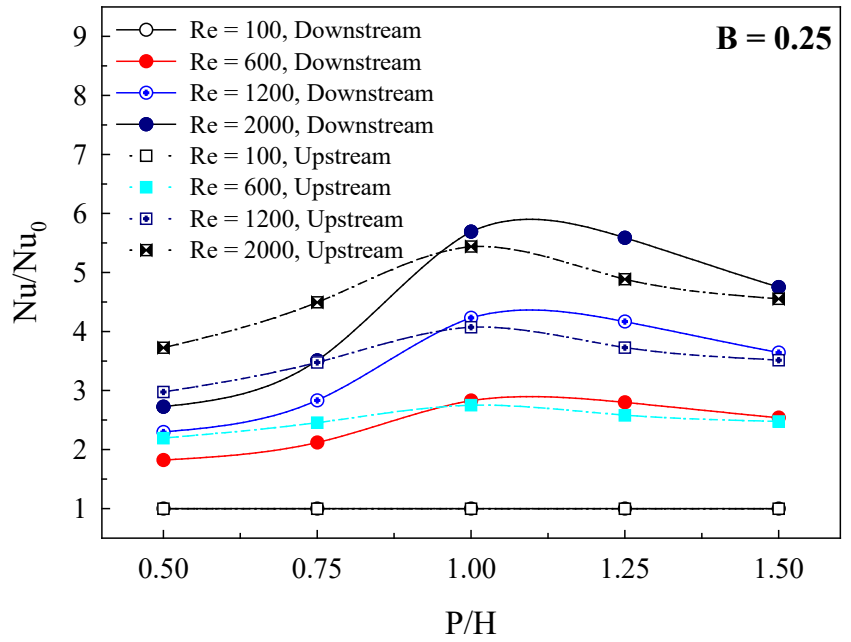

(e)

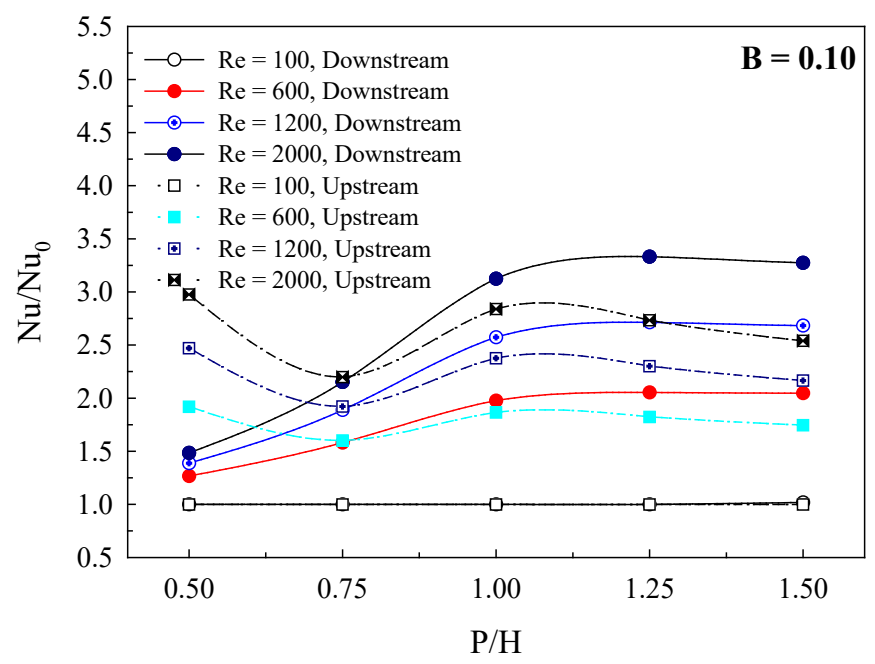

(b)

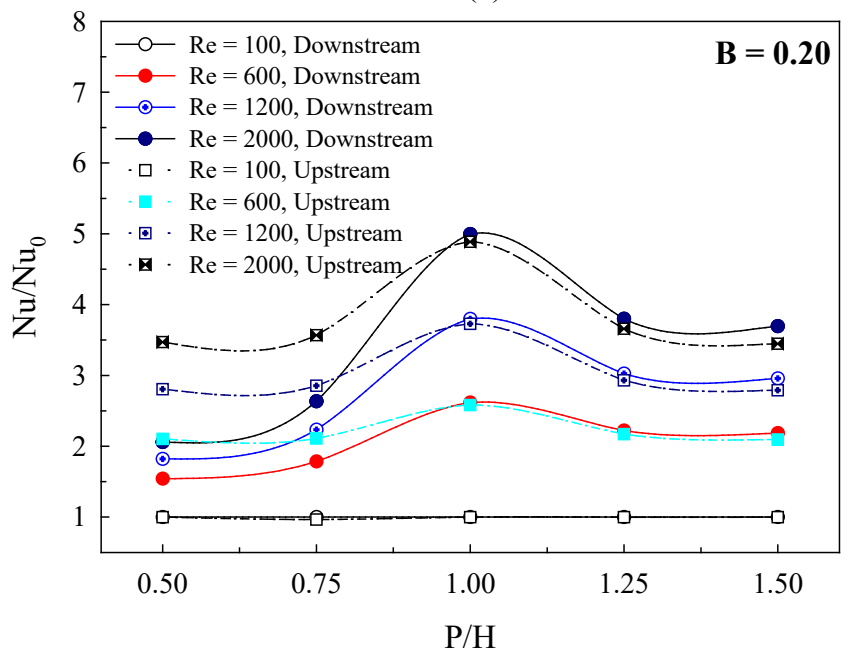

(d)

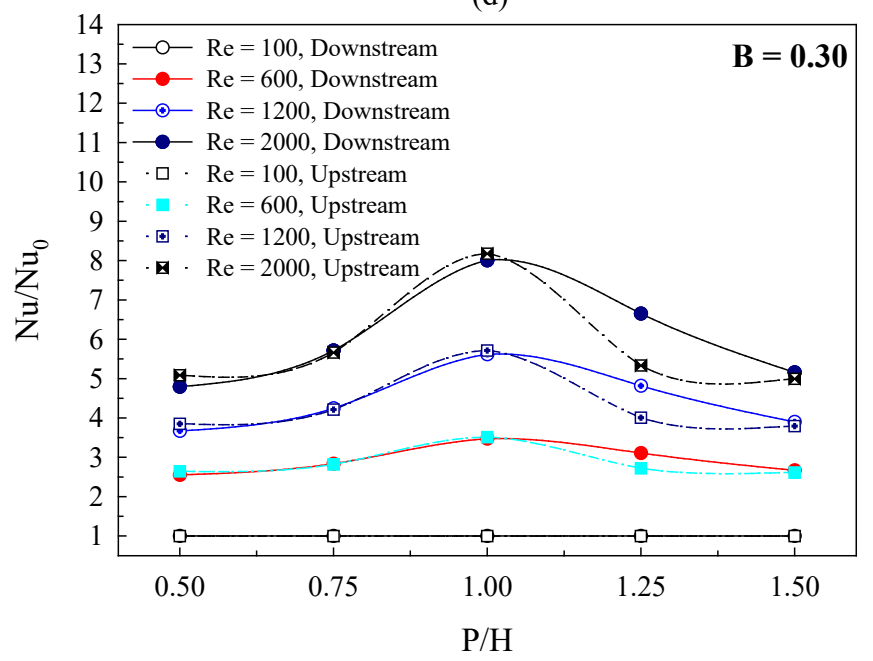

(f)

Fig. $17 \mathrm{Nu} / \mathrm{Nu} 0$ vs $\mathrm{P} / \mathrm{H}$ for (a) $\mathrm{B}=0.05$, (b) $\mathrm{B}=0.10$, (c) $\mathrm{B}=0.15$, (d) $\mathrm{B}=0.20$, (e) $\mathrm{B}=0.25$ and (f) $\mathrm{B}=0.30$.

The tested section inserted with WTR at $\mathrm{B}=0.30$ provides the highest heat transfer rate, while the $\mathrm{B}=0.05$ performs the opposite result. The local Nusselt number distributions on the heat transfer surface of the heat exchanger duct inserted with WTR at various $\mathrm{P} / \mathrm{H}$ values are plotted as Fig. 12 for $\mathrm{B}=0.25, \mathrm{Re}=800$ and V-Downstream arrangement. The similar pattern of heat transfer behavior at various
$\mathrm{P} / \mathrm{H}$ values is detected. The optimum $\mathrm{P} / \mathrm{H}$ values may bring the best heat transfer rate and thermal performance. The change of the flow direction brings the variation of the heat transfer characteristic in the heat exchanger duct (see Fig. 13). The greatest heat transfer regime is detected in front of the WTR in all cases. 


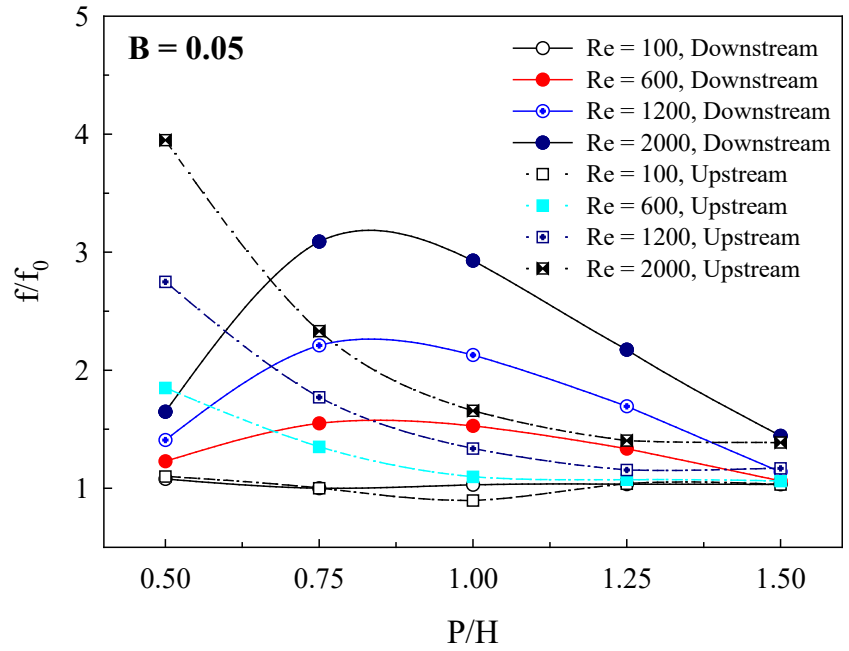

(a)

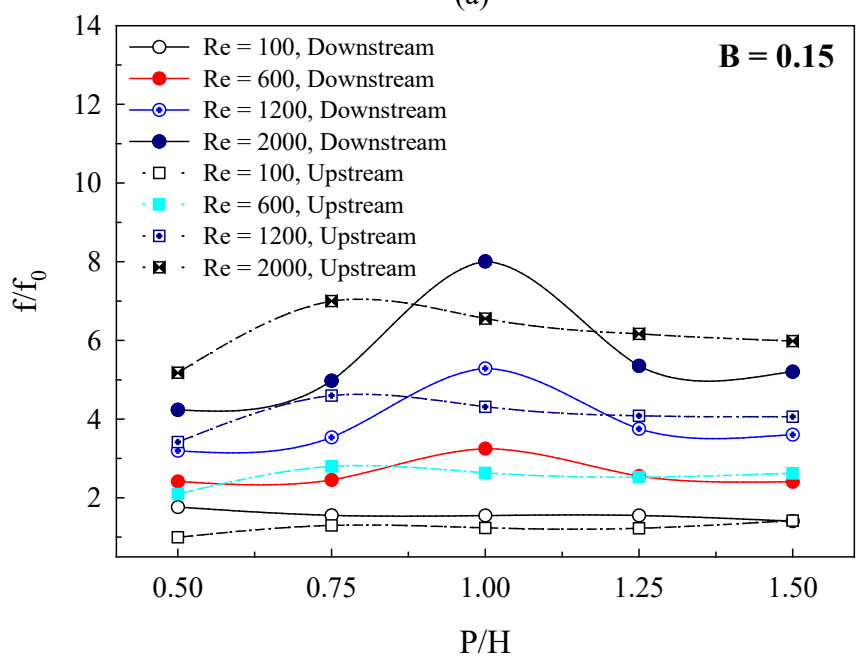

(c)

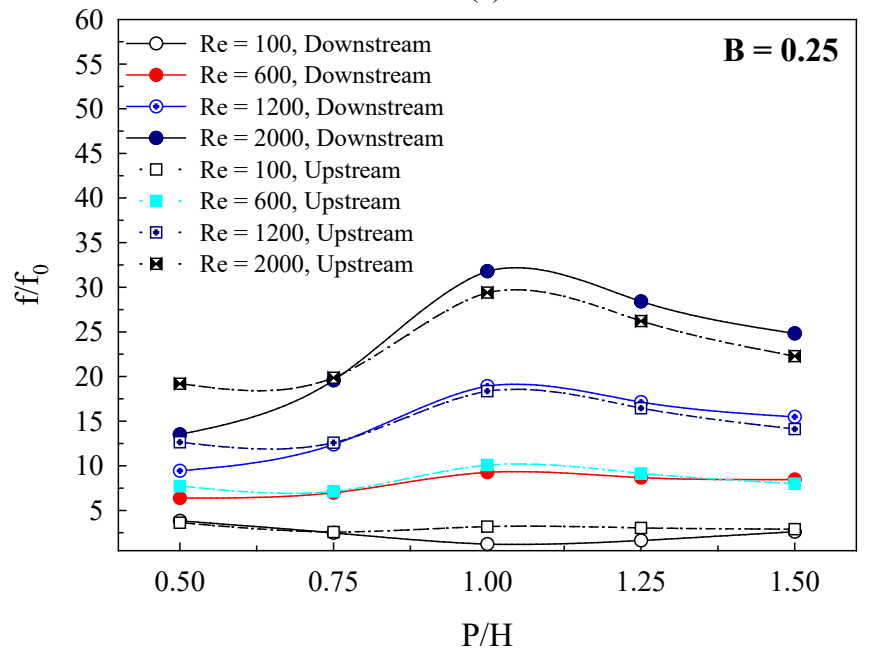

(e)

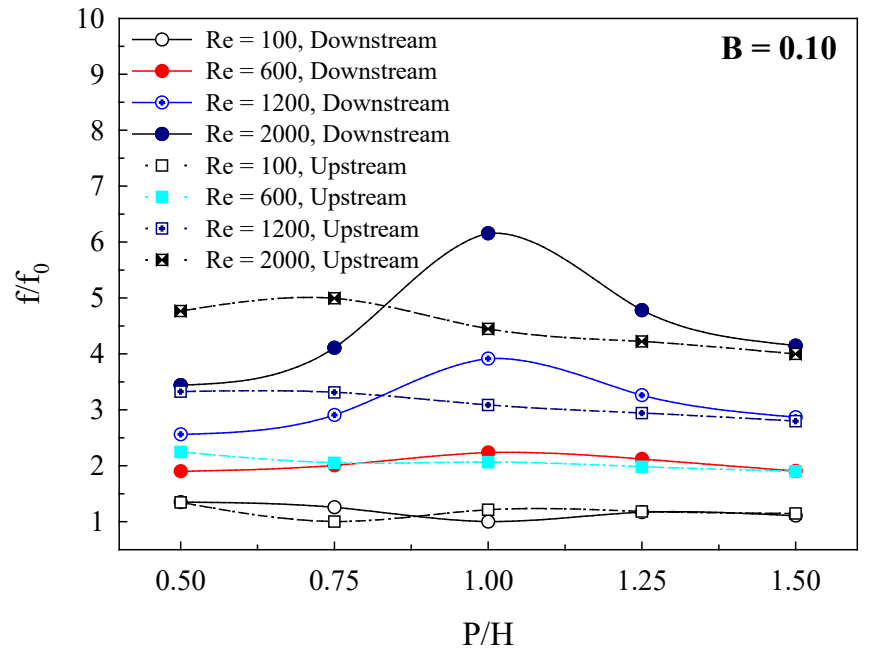

(b)

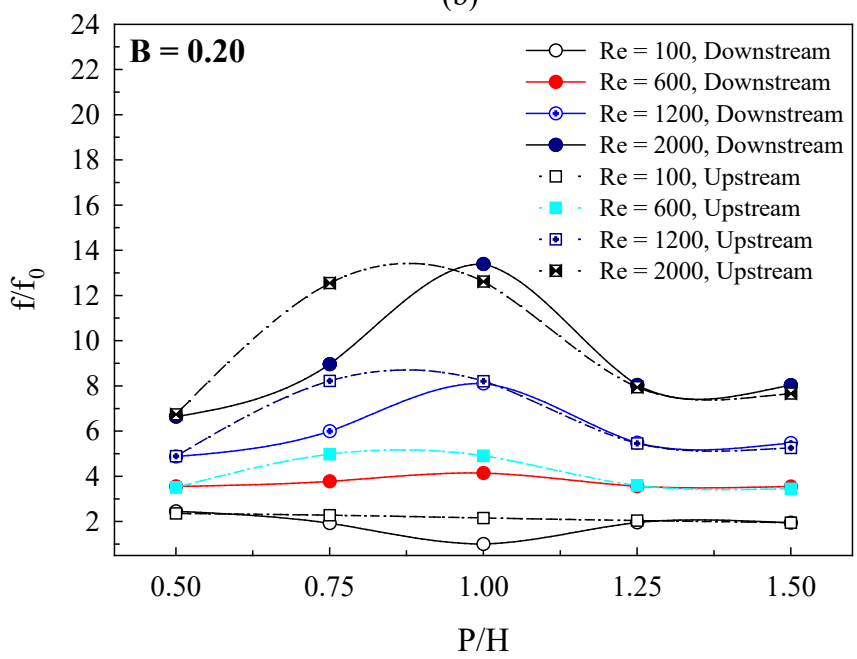

(d)

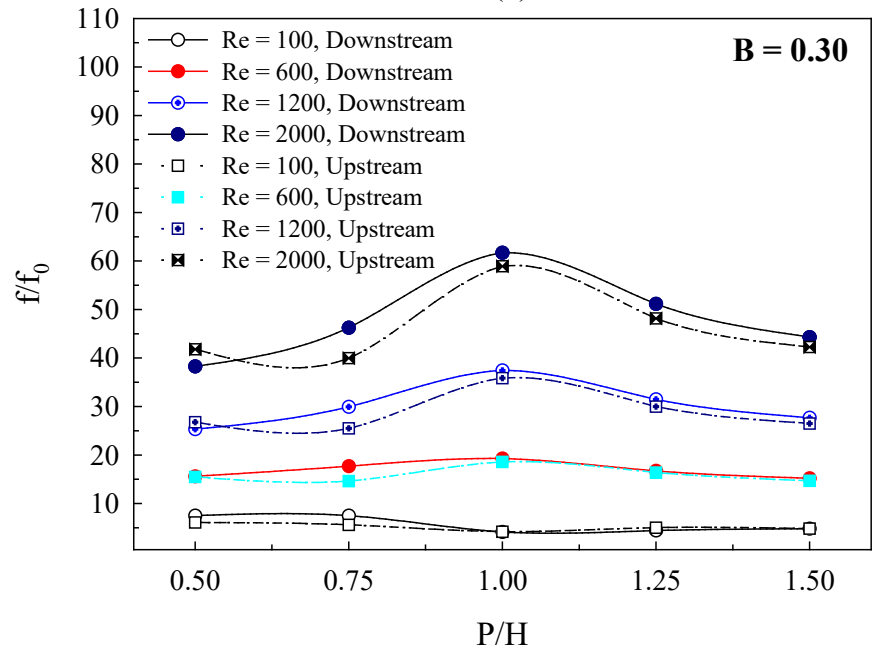

(f)

Fig. $18 \mathrm{f} / \mathrm{f}_{0}$ vs $\mathrm{P} / \mathrm{H}$ for (a) $\mathrm{B}=0.05$, (b) $\mathrm{B}=0.10$, (c) $\mathrm{B}=0.15$, (d) $\mathrm{B}=0.20$, (e) $\mathrm{B}=0.25$ and (f) $\mathrm{B}=0.30$.

\subsection{Influence of Reynolds number}

The air velocity for the heat exchanger square duct placed with WTR is presented in term of Reynolds number. The Reynolds number around $100-2000$ is considered for the current work. The relations of the $\mathrm{Nu} / \mathrm{Nu}_{0}, \mathrm{f} / \mathrm{f}_{0}$ and TEF with Reynolds numbers at various cases are illustrated as Figs. 14, 15 and 16, respectively, while the variations of the $\mathrm{Nu} / \mathrm{Nu}_{0}, \mathrm{f} / \mathrm{f}_{0}$ and $\mathrm{TEF}$ with $\mathrm{P} / \mathrm{H}$ values are depicted as Figs. 17, 18 and 19 , respectively.

As the figure, the heat transfer rate rises when augmenting the Reynolds number for all examinations. The $\mathrm{Re}=100$ gives the lowest value of heat transfer rate, while the $\mathrm{Re}=2000$ performs the opposite trend. The increment of the Reynolds number has directly affect for the development of the vortex strength. 


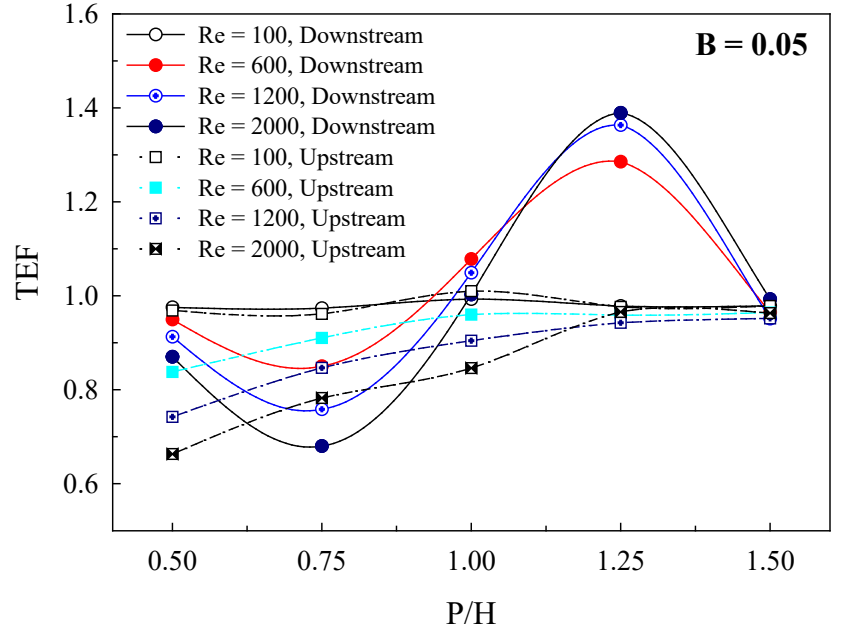

(a)

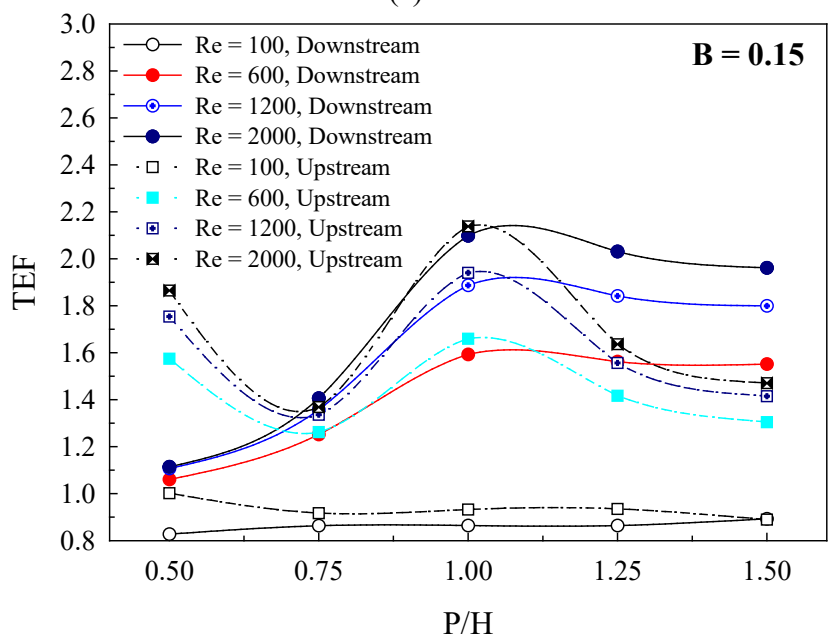

(c)

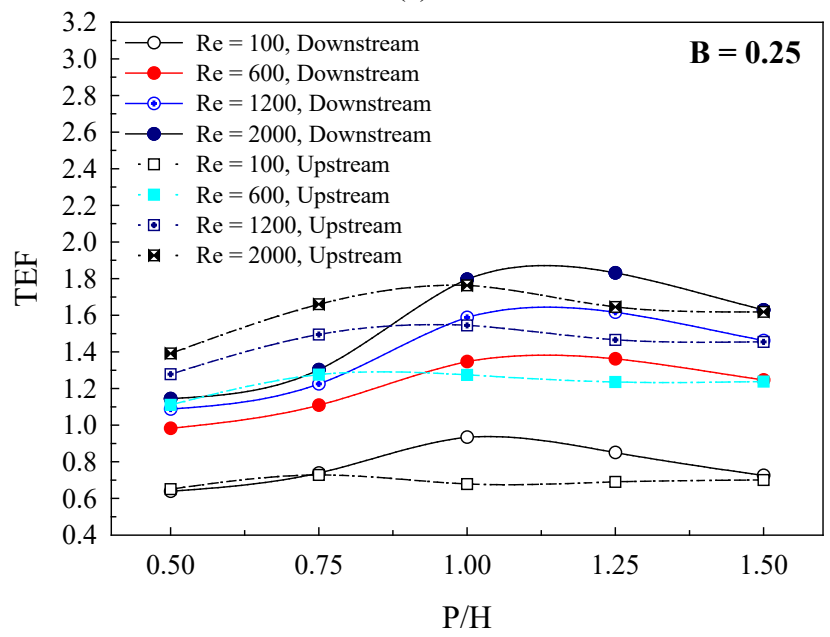

(e)

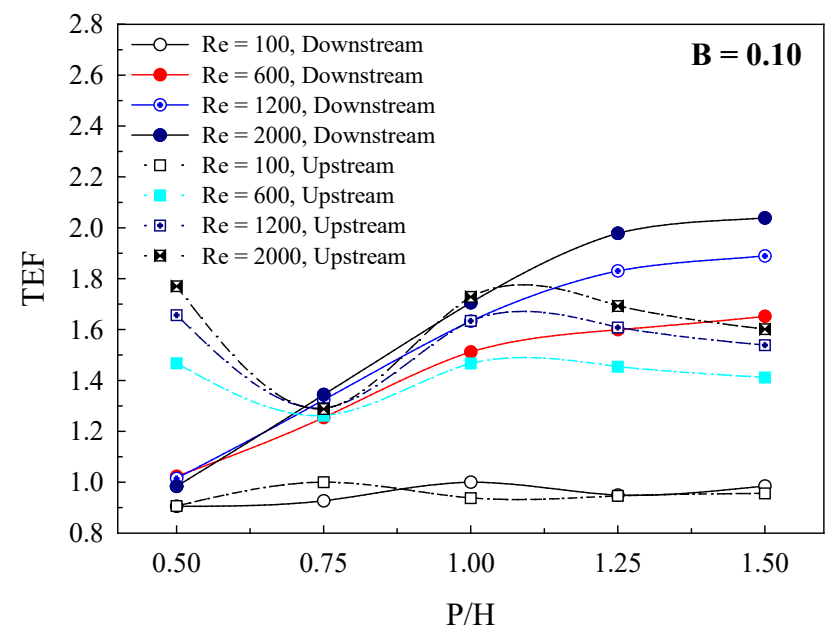

(b)

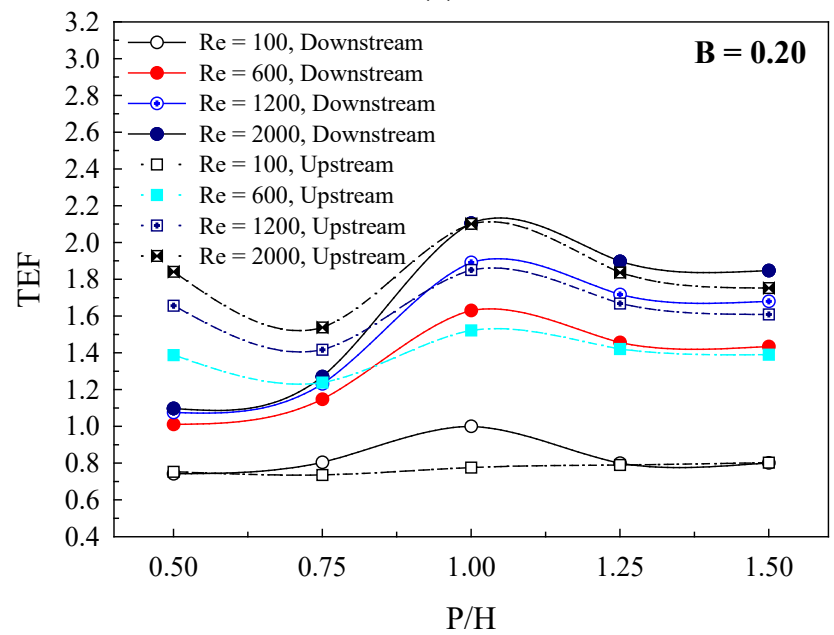

(d)

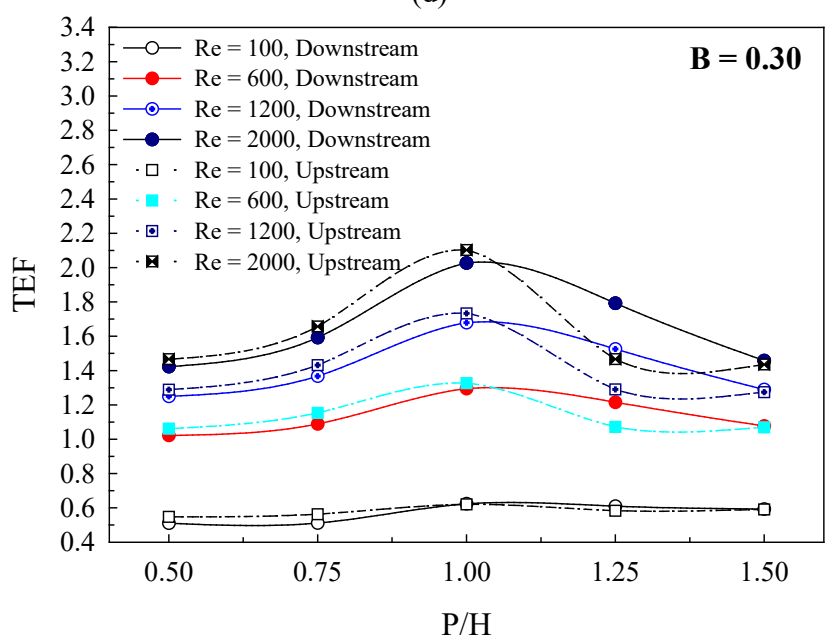

(f)

Fig. 19 TEF vs $\mathrm{P} / \mathrm{H}$ for (a) $\mathrm{B}=0.05$, (b) $\mathrm{B}=0.10$, (c) $\mathrm{B}=0.15$, (d) $\mathrm{B}=0.20$, (e) $\mathrm{B}=0.25$ and (f) $\mathrm{B}=0.30$.

The vortex strength increases when augmenting the air velocity. The impingement of the vortex flow on the heat transfer surface also augments when rising the air velocity. These behaviors are the reason for heat transfer increment. The $\mathrm{Nu} / \mathrm{Nu}_{0}$ in the heating duct inserted with WTR at the $\operatorname{Re}=100$ is close to the smooth duct for all studied cases $\left(\mathrm{Nu} / \mathrm{Nu}_{0} \approx 1\right)$. At $\mathrm{Re}=2000$ and $\mathrm{V}$-Downstream, the $\mathrm{Nu} / \mathrm{Nu}_{0}$ in the tested section placed with WTR is around $1.03-4.80,1.00-5.72$, $1.43-8.01,1.80-6.66$ and $1.12-5.16$ for $\mathrm{P}=0.5 \mathrm{H}, 0.75 \mathrm{H}, \mathrm{H}, 1.25 \mathrm{H}$ and $1.5 \mathrm{H}$, respectively. Considering at V-Upstream and $\mathrm{Re}=2000$, the installation of the WTR in the heat exchanger duct improves the heat transfer rate higher than the smooth duct around 1.05 - 5.09, $1.04-$ $5.67,1.00-8.18,1.08-5.34$ and $1.07-5.00$ times, respectively, for $\mathrm{P}$ $=0.5 \mathrm{H}, 0.75 \mathrm{H}, \mathrm{H}, 1.25 \mathrm{H}$ and $1.5 \mathrm{H}$. The friction loss in the heating section placed with WTR slightly increases when increasing the Reynolds number for $\mathrm{B} \leq 0.10$. 
At high flow blockage ratio $(\mathrm{B}>0.10)$, the friction loss extremely enhances when rising the Reynolds number. Considering at $\mathrm{Re}=100$ and V-Downstream, the pressure loss in the heating duct placed with WTR is around $1.08-7.51,1.00-7.51,1.03-4.13,1.03-4.43$ and $1.03-4.80$, respectively, for $\mathrm{P}=0.5 \mathrm{H}, 0.75 \mathrm{H}, \mathrm{H}, 1.25 \mathrm{H}$ and $1.5 \mathrm{H}$. The pressure loss for the heat exchanger duct placed with V-Upstream is greater than the plain duct around $1.10-6.10,1.00-5.60,1.00-4.20$, $1.04-5.04$ and $1.03-4.84$ times for $\mathrm{P} / \mathrm{H}=0.50,0.75,1.00,1.25$ and 1.50 , respectively, at $\mathrm{Re}=100$. At $\mathrm{Re}=2000$ and $\mathrm{V}$-Downstream, the $\mathrm{f} / \mathrm{f}_{0}$ is around $1.65-38.29,3.09-46.27,2.93-61.70,2.17-51.17$ and $1.44-44.32$ for $\mathrm{P} / \mathrm{H}=0.50,0.75,1.00,1.25$ and 1.50 , respectively. Seeing at $\mathrm{Re}=2000$ of V-Upstream, the friction loss in the heat exchanger duct is found to be higher than the smooth duct with no WTR around $3.95-41.82,2.33-39.99,1.66-58.92,1.41-48.17$ and $1.39-42.27$ times, respectively, for $\mathrm{P} / \mathrm{H}=0.50,0.75,1.00,1.25$ and 1.50 .

Considering at $\mathrm{P}=0.5 \mathrm{H}$ and $\mathrm{V}$-Upstream, the TEF of the heat exchanger duct inserted with WTR tends to increase when enhancing the Reynolds number, except for $\mathrm{B}=0.05$. The TEF of the heat exchanger duct inserted with V-Downstream WTR slightly decreases when increasing the Reynolds number, except for $\mathrm{B}=0.30$. For $\mathrm{P}=$ $0.75 \mathrm{H}-1.5 \mathrm{H}$ of both flow directions, the TEF in the heating section enhances when augmenting the Reynolds number for $\mathrm{B} \geq 0.10$, but slightly decreases for $\mathrm{B}=0.05$.

\subsection{Influence of blockage ratio}

The numerical result reveals that the heat transfer rate in the heating section placed with WTR enhances when augmenting the height of the WTR. The lowest heat transfer rate is detected at $\mathrm{B}=0.05$, while the highest heat transfer rate is found at $\mathrm{B}=0.30$. This is because the vortex strength in the tested section rises when rising the flow blockage ratio. In the range studies, the maximum heat transfer rate in the heating section equipped with WTR is around 1.80, 3.33, 4.20, 5.00, 5.69 and 8.18 times above the smooth duct, respectively, for $\mathrm{B}=0.05,0.10$, $0.15,0.20,0.25$ and 0.30 .

The friction loss in the heat exchanger duct also increases when rising the flow blockage ratio of the WTR, especially, at B $\geq 0.25$. The pressure loss in the heating duct inserted with WTR is found to be maximum around $3.95,6.16,8.01,13.38,31.82$ and 61.70 times above the smooth duct with no WTR, respectively, for $\mathrm{B}=0.05,0.10,0.15$, $0.20,0.25$ and 0.30 .

The optimum TEF in the heating section equipped with $\mathrm{V}$ Downstream WTR at $\mathrm{P}=0.5 \mathrm{H}, 0.75 \mathrm{H}, \mathrm{H}, 1.25 \mathrm{H}$ and $1.5 \mathrm{H}$ is around $1.42,1.59,2.11,2.03$ and 2.04, which is found at $\mathrm{B}=0.30,0.30,0.20$, 0.15 and 0.10 , respectively. Considering at $\mathrm{V}$-Upstream case, the maximum TEF in the tested section for $\mathrm{P}=0.5 \mathrm{H}, 0.75 \mathrm{H}, \mathrm{H}, 1.25 \mathrm{H}$ and $1.5 \mathrm{H}$ is around $1.86,1.66,2.14,1.84$ and 1.76 , respectively, at $\mathrm{B}=0.15$, $0.25,0.15,0.20$ and 0.20 .

\subsection{Influence of pitch ratio}

The peak of $\mathrm{Nu} / \mathrm{Nu}_{0}$ in the heat exchanger duct equipped with WTR for $\mathrm{B}=0.05,0.10,0.15,0.20,0.25$ and 0.30 is detected at $\mathrm{P} / \mathrm{H}=1.25,1.25$, $1.00,1.00,1.00-1.25$ and 1.00 , respectively, for V-Downstream case. For V-Upstream case, the highest heat transfer rate in the heating system placed with WTR is found at $\mathrm{P} / \mathrm{H}=1$ for $\mathrm{B}>0.05$. The $\mathrm{B}=$ 0.05 of $\mathrm{V}$-Upstream cases gives close values of TEF for all $\mathrm{P} / \mathrm{H}$ values.

The highest $\mathrm{f} / \mathrm{f}_{0}$ in the square duct heat exchanger inserted with $\mathrm{V}$ Downstream WTR is found at $\mathrm{P} / \mathrm{H}=1.00$ for $\mathrm{B}>0.05$, while detected at $\mathrm{P}=0.75 \mathrm{H}$ for $\mathrm{B}=0.05$. For $\mathrm{V}$-Upstream $\mathrm{WTR}$, the peak of $\mathrm{f} / \mathrm{f}_{0}$ in the tested section is found at $\mathrm{P} / \mathrm{H}$ around $0.5,0.50-0.75,0.75,0.75-1,1$ and 1 , respectively, for $\mathrm{B}=0.05,0.10,0.15,0.20,0.25$ and 0.30 .

The maximum value of TEF in the heat exchanger square duct equipped with V-Downstream WTR for $\mathrm{B}=0.05,0.10,0.15,0.20,0.25$ and 0.30 is detected at $\mathrm{P}=1.25 \mathrm{H}, 1.25 \mathrm{H}, 1-1.25 \mathrm{H}, \mathrm{H}, \mathrm{H}$ and $\mathrm{H}$, respectively, while the optimum TEF for the V-Upstream case is detected at $\mathrm{P} / \mathrm{H}=1$ for all blockage ratios.

\subsection{Influence of flow direction}

For $\mathrm{P} / \mathrm{H}=0.5$, the $\mathrm{V}$-Upstream direction provides higher heat transfer rate than the $\mathrm{V}$-Downstream for $\mathrm{B}>0.05$, while the heat transfer rate at $\mathrm{B}=0.05$ of both directions is found to be in similar values for all Reynolds numbers. At $\mathrm{P} / \mathrm{H}=0.75$ and $\mathrm{B}=0.05,0.10$ and 0.30 , the trends of the average Nusselt number for both flow directions are very close. For $\mathrm{P} / \mathrm{H}=0.75$ at $\mathrm{B}=0.15-0.25$, the $\mathrm{V}$-Downstream arrangement gives lower heat transfer rate than the V-Upstream arrangement. At $\mathrm{P}=\mathrm{H}$, the installation of $\mathrm{V}$-Downstream direction performs greater Nusselt number ratio than the V-Upstream direction, except for $\mathrm{B}=0.30$. The $\mathrm{V}$-Downstream WTR with $\mathrm{P} / \mathrm{H}=1.25$ provides greater Nusselt number than the V-Upstream WTR, except for $\mathrm{B}=0.10$ and 0.15 . For $\mathrm{P}=1.5 \mathrm{H}$, the insertion of the $\mathrm{V}$-Downstream WTR in the tested section brings higher heat transfer rate than the VUpstream WTR for $\mathrm{B}=0.20-0.30$, but lower for $\mathrm{B}=0.10$ and 0.15 . The placement of WTR in the tested section with $\mathrm{B}=0.05$ and $\mathrm{P} / \mathrm{H}=$ 1.5 with different flow direction has no effect for heat transfer rate.

At $\mathrm{P}=0.5 \mathrm{H}$, the friction loss in the heat exchanger duct inserted with WTR is very close when change flow direction for $\mathrm{B}=0.05-$ 0.20 . The V-Downstream WTR gives higher friction loss than the VUpstream WTR when $\mathrm{B}>0.20$ for $\mathrm{P} / \mathrm{H}=0.5$. At $\mathrm{P} / \mathrm{H}=0.75$, the pressure loss in the heat exchanger section installed with WTR is found to be in similar values for both flow directions at $\mathrm{B}<0.30$. Considering at $\mathrm{B}=0.30$ of $\mathrm{P} / \mathrm{H}=0.75$, the WTR with $\mathrm{V}$-Downstream arrangement provides higher friction loss than the $\mathrm{V}$-Upstream arrangement in all Reynolds numbers. For $\mathrm{P}=\mathrm{H}$ and $1.25 \mathrm{H}$ at $\mathrm{B}<0.30$, the addition of the WTR with V-Downstream direction brings nearly values of the pressure loss as the V-Upstream direction. At $\mathrm{P}=\mathrm{H}$ and $1.25 \mathrm{H}$ at $\mathrm{B}=0.30$, the $\mathrm{V}$-Downstream case performs slightly higher friction loss than the $\mathrm{V}$ Upstream cases. At $\mathrm{P} / \mathrm{H}=1.5$ and $\mathrm{B}<0.25$, the difference of flow direction in the tested section inserted with WTR has no effect for the variations of the friction loss. For $\mathrm{P}=1.5 \mathrm{H}$ and $\mathrm{B} \geq 0.25$, the $\mathrm{V}$ Downstream arrangement offers greater friction loss than the $\mathrm{V}$ Upstream arrangement.

\section{CONCLUSION}

The numerical investigations on convective heat transfer in the heat exchanger square duct equipped with WTR are presented. The Reynolds number around $100-2000$ at the entry condition is considered for the present work. The numerical problem is solved with the finite volume method. The influences of WTR parameters; height, pitch, flow direction, on flow topology and heat transfer structure are discussed. The conclusion of the present investigation can conclude as follows.

The WTR in the heat exchanger duct can produce the vortex flow through the tested section in all cases. The vortex flow will disturb the thermal boundary layer on the heat transfer surface that the reason for heat transfer rate and thermal performance augmentations. The better fluid mixing in the testing duct is another cause for the increment of heat transfer rate and performance.

The vortex strength in the duct enhances when enhancing the flow blockage ratio and Reynolds number that leads to the augmentation of heat transfer rate. The friction loss in the heating section also increases when increasing the flow blockage ratio and Reynolds number.

The variation of the flow directions (V-Downstream and $\mathrm{V}$ Upstream) effects for the change of the flow topology and heat transfer characteristics in the heat exchanger duct inserted with WTR.

In the range studies, the optimum thermal enhancement factor of $\mathrm{V}$-Downstream arrangement is around 2.11 for $\mathrm{B}=0.20$ and $\mathrm{P}=\mathrm{H}$, while around 2.14 for $\mathrm{B}=0.15$ and $\mathrm{P}=\mathrm{H}$ of $\mathrm{V}$-Upstream direction.

\section{NOMENCLATURE}

b WTR height, $\mathrm{m}$

B blockage ratio, $\mathrm{b} / \mathrm{H}$

$\mathrm{D}_{\mathrm{h}} \quad$ hydraulic diameter of duct, $\mathrm{m}$ 
f friction factor

$\mathrm{H} \quad$ duct height, $\mathrm{m}$

$\mathrm{h} \quad$ convective heat transfer coefficient, $\mathrm{W} \mathrm{m}^{-2} \mathrm{~K}^{-1}$

$\mathrm{k}$ thermal conductivity, $\mathrm{W} \mathrm{m}^{-1} \mathrm{~K}^{-1}$

$\mathrm{L} \quad$ periodic length of the numerical model, $\mathrm{m}$

$\mathrm{Nu} \quad$ Nusselt number $(=\mathrm{hDh} / \mathrm{k})$

$\mathrm{P} \quad$ pitch distance between WTRs, $\mathrm{m}$

$\mathrm{p} \quad$ static pressure, $\mathrm{Pa}$

Re Reynolds number

$\mathrm{T}$ temperature, $\mathrm{K}$

$\bar{u} \quad$ mean velocity in channel, $\mathrm{m} \mathrm{s}^{-1}$

\section{Greek letter}

$\rho \quad$ density, $\mathrm{kg} \mathrm{m}^{-3}$

$\mu \quad$ dynamic viscosity, $\mathrm{kg} \mathrm{m}^{-1} \mathrm{~s}^{-1}$

Subscript

$0 \quad$ plain duct

pp pumping power

Abbreviation

WTR Wavy Thin Rib

TEF Thermal Enhancement Factor $\left(=\left(\mathrm{Nu} / \mathrm{Nu}_{0}\right) /\left(\mathrm{f} / \mathrm{f}_{0}\right)^{1 / 3}\right)$

\section{ACKNOWLEDGMENTS}

The authors would like to thank Assoc. Prof. Dr. Pongjet Promvonge for suggestions. This research was funded by King Mongkut's University of Technology North Bangkok, Contract no. KMUTNB-64KNOW-15.

\section{REFERENCES}

Ahmed, H.E., Salman, B.H., and Kerbeet, A.S., 2019, "Heat Transfer Enhancement of Turbulent Forced Nanofluid Flow in A Duct Using Triangular Rib," International Journal of Heat and Mass Transfer, 134, $30-40$.

https://doi.org/10.1016/j.ijheatmasstransfer.2018.12.163

Bahiraei, M., Mazaheri, N., and Moayedi, H., 2020, "Employing Vshaped Ribs and Nanofluid as Two Passive Methods to Improve Second Law Characteristics of Flow within A Square Channel: A Two-phase Approach", International Journal of Heat and Mass Transfer, 151, Article 119419.

https://doi.org/10.1016/j.ijheatmasstransfer.2020.119419

Bahiraei, M., Mazaheri, N., and Rizehvandi, A., 2019b, "Application of A Hybrid Nanofluid Containing Graphene Nanoplatelet-platinum Composite Powder in A Triple-tube Heat Exchanger Equipped with Inserted Ribs," Applied Thermal Engineering, 149, 588-601.

https://doi.org/10.1016/j.applthermaleng.2018.12.072

Bahiraei, M., Mazaheri, N., Hosseini, Y., and Moayedi, H., 2019a, “A Two-phase Simulation for Analyzing Thermohydraulic Performance of $\mathrm{Cu}$-water Nanofluid within A Square Channel Enhanced with $90^{\circ} \mathrm{V}-$ shaped Ribs," International Journal of Heat and Mass Transfer, 145, Article 118612.

https://doi.org/10.1016/j.ijheatmasstransfer.2019.118612

Bai, W., Chen, W., Yang, L., and Chyu, M.K., 2019b, "Numerical Investigation on Heat Transfer and Pressure Drop of Pin-fin Array under The Influence of Rib Turbulators Induced Vortices," International Journal of Heat and Mass Transfer, 129, 735-745. https://doi.org/10.1016/j.ijheatmasstransfer.2018.10.022

Bai, W., Liang, D., Chen, W., and Chyu, M.K., 2019a, "Investigation of Ribs Disturbed Entrance Effect of Heat Transfer and Pressure Drop in Pin-fin Array," Applied Thermal Engineering, 162, Article 114214. https://doi.org/10.1016/j.applthermaleng.2019.114214
Cengel, Y.A., and Ghajar, A.J., 2015, "Heat and Mass Transfer: Fundamentals \& Applications," Fifth edition in SI Units, McGraw-Hill Education,

Chai, L., Wang, L., and Bai, X., 2019, "Thermohydraulic Performance of Microchannel Heat Sinks with Triangular Ribs on Sidewalls - Part 2: Average Fluid Flow and Heat Transfer Characteristics," International Journal of Heat and Mass Transfer, 128, 634-648. https://doi.org/10.1016/j.ijheatmasstransfer.2018.09.027

Li, H., Yu, T., Wang, D., and Xu, H., 2019b, "Heat-transfer Enhancing Mechanisms Induced by The Coherent Structures of Wall-bounded Turbulence in Channel with Rib," International Journal of Heat and Mass Transfer, 137, 446-460.

https://doi.org/10.1016/j.ijheatmasstransfer.2019.03.122

Li, Y., Rao, Y., Wang, D., Zhang, P., and Wu, X., 2019a, "Heat Transfer and Pressure Loss of Turbulent Flow in Channels with Miniature Structured Ribs on One Wall," International Journal of Heat and Mass Transfer, 131, 584-593.

https://doi.org/10.1016/j.ijheatmasstransfer.2018.11.067

Liu, P., Lv, J., Shan, F., Liu, Z., and Liu, W., 2019, "Effects of Rib Arrangements on the Performance of A Parabolic Trough Receiver with Ribbed Absorber Tube," Applied Thermal Engineering, 156, 1-13. https://doi.org/10.1016/j.applthermaleng.2019.04.037

Luan, Y., Yang, L., Bu, S., Sun, T., Sun, H., and Zunino, P., 2019, "Effect of Connecting Holes on Flow and Heat Transfer in A Two-pass Channel with and without Rib Turbulators," International Journal of Heat and Mass Transfer, 133, 80-95.

https://doi.org/10.1016/j.ijheatmasstransfer.2018.12.043

Patankar, S.V., Liu, C.H., and Sparrow, E.M., 1977, "Fully Developed Flow and Heat Transfer in Ducts Having Streamwise-Periodic Variations of Cross-Sectional Area," Journal of Heat Transfer, 99, 180186.

https://doi.org/10.1115/1.3450666

Patel, Y.M., Jain, S.V., and Lakhera, V.J., 2020, “Thermo-hydraulic Performance Analysis of A Solar Air Heater Roughened with Reverse NACA Profile Ribs," Applied Thermal Engineering, 170, Article 114940.

https://doi.org/10.1016/j.applthermaleng.2020.114940

Wang, G., Chen, T., Tian, M., and Ding, G., 2020, "Fluid and Heat Transfer Characteristics of Microchannel Heat Sink with Truncated Rib on Sidewall," International Journal of Heat and Mass Transfer, 148, Article 119142.

https://doi.org/10.1016/j.ijheatmasstransfer.2019.119142

Wang, G., Qian, N., and Ding, G., 2019, "Heat Transfer Enhancement in Microchannel Heat Sink with Bidirectional Rib," International Journal of Heat and Mass Transfer, 136, 597-609.

https://doi.org/10.1016/j.ijheatmasstransfer.2019.02.018

Yuan, N., Bi, D., Zhai, Y., Jin, Y., Li, Z., and Wang, H., 2020, "Flow and Heat Transfer Performance of Supercritical Pressure Carbon Dioxide in Pipes with Discrete Double Inclined Ribs," International Journal of Heat and Mass Transfer, 149, Article 119175. https://doi.org/10.1016/j.ijheatmasstransfer.2019.119175

Zheng, D., Wang, X., and Yuan, Q., 2019, "The Flow and Heat Transfer Characteristics in A Rectangular Channel with Convergent and Divergent Slit Ribs," International Journal of Heat and Mass Transfer, 141, 464-475.

https://doi.org/10.1016/j.ijheatmasstransfer.2019.06.060 